Article

\title{
A Fuzzy Network DEA Approach to the Selection of Advanced Manufacturing Technology
}

\section{Tim Lu}

Citation: Lu, T. A Fuzzy Network DEA Approach to the Selection of Advanced Manufacturing Technology. Sustainability 2021, 13, 4236. https:// doi.org/10.3390/su13084236

Academic Editors: Daryl Powell, David Romero and Paolo Gaiardelli

Received: 4 March 2021

Accepted: 8 April 2021

Published: 11 April 2021

Publisher's Note: MDPI stays neutral with regard to jurisdictional claims in published maps and institutional affiliations.

Copyright: (C) 2021 by the author. Licensee MDPI, Basel, Switzerland. This article is an open access article distributed under the terms and conditions of the Creative Commons Attribution (CC BY) license (https:// creativecommons.org/licenses/by/ $4.0 /)$.
Department of Marketing and Logistics, Vanung University, Zhongli, Taoyuan 320, Taiwan; timlu@vnu.edu.tw

\begin{abstract}
The selection of advanced manufacturing technologies (AMTs) is an essential yet complex decision that requires careful consideration of various performance criteria. In real-world applications, there are cases that observations are difficult to measure precisely, observations are represented as linguistic terms, or the data need to be estimated. Since the growth of engineering sciences has been the key reason for the increased utilization of AMTs, this paper develops a fuzzy network data envelopment analysis (DEA) to the selection of AMT alternatives considering multiple decisionmakers (DMs) and weight restrictions when the input and output data are represented as fuzzy numbers. By viewing the multiple DMs as a network one, the data provided by each DM can then be taken into account in evaluating the overall performances of AMT alternatives. In the solution process, we obtain the overall and DMs efficiency scores of each AMT alternative at the same time, and a relationship in which the former is a weighted average of the latter is also derived. Since the final evaluation results of AMTs are fuzzy numbers, a ranking procedure is employed to determine the most preferred one. An example is used to illustrate the applicability of the proposed methodology.
\end{abstract}

Keywords: data envelopment analysis; advanced manufacturing technology; network; fuzzy set

\section{Introduction}

In order to respond quickly and effectively to rapidly changing needs of customers and to maintain a high level of competitiveness in the global arena, manufactures have sought the adoption of advanced manufacturing technologies (AMTs) such as robots, flexible manufacturing systems, computer-integrated manufacturing, etc. The use AMTs appears to herald a future in which value chains are shorter, more collaborative, and offer significant sustainability [1]. Additionally, the adoption of AMTs might help spawn wider applications for additive manufacturing, which is inherently less wasteful than traditional subtractive methods of production and a driving force for improved industrial sustainability [2]. In other words, firms can capture from AMTs to speed up sustainable manufacturing for greater flexibility and less waste [3].

Data envelopment analysis (DEA) is a well-established nonparametric approach used to evaluate the relative efficiency of a set of comparable entities called decision-making units (DMUs) with multiple inputs and outputs. Since there is no need to specify relative importance weights for performance criteria, DEA has been widely applied for AMT selection and justification [4]. The advantage of using DEA is that it does not require a priori specification of input and output weights and by letting these weights run freely to obtain optimal weights for all input/output items of each DMU. In other words, the difference between the multi-criteria decision-making method and DEA is that the former intends to identify the trade-off precisely, and the latter leaves some weight flexibility [5].

Several studies in the literature have applied DEA models for AMT selection and justification problems [6-16]. Nevertheless, these methods for AMT evaluations are considered only the case of a single decision-maker (DM). The changing economic environment is becoming more and more complex, making a decision analysis almost impossible for 
a single DM to consider all aspects of a problem. For example, investigating new technologies or creative applications may involve assimilating a large amount of information and exploring different ideas. Group decision-making is an important part and plays a critical role in decision science and can be considered as a situation in which DMs need to obtain the best solution from a set of alternatives considering their preferences and opinions. In such a situation, this kind of study is further compounded when considered within a number of multiple DMs. When observations are uncertain, one approach is to represent these uncertain values directly by fuzzy numbers [17]. Under the framework of DEA, different approaches for measuring efficiency in fuzzy environments have been proposed [18-24]. A comprehensive bibliography of these approaches and applications can be found in Hatami-Marbini et al. [25] and Emrouznejad and Tavana [26]. Recently, fuzzy network DEA approaches receive more attention [27-30], and there are also novel applications of the fuzzy network DEA (refer to those described in Kao [31]).

DEA models do not require a priori specification of input and output weights (or multipliers) and let these weights run freely to obtain optimal weights for all inputs and outputs of each DMU without imposing any constraints on these weights. However, if left to run freely, the weights may lead to overly optimistic, even unrealistic, measures of efficiency [32]. Moreover, existing fuzzy DEA studies did not consider the case of multiple DMs. In this study, we develop a decision-making model considering multiple judgments of DMs and incorporating weight restrictions into analysis using a fuzzy network DEA to the selection of AMT alternatives. It makes a number of contributions to the literature on fuzzy decision-making under DEA frameworks. First, this paper takes into account all the judgments of DMs to measure the overall efficiency and the efficiencies of DMs at the same time, and a mathematical relationship is derived between them. Second, the proposed model is based on the $\alpha$ level-based approach, which is the most popular one in developing fuzzy DEA models [25], to formulate the fuzzy network DEA. When the input and output data are all crisp numbers, the fuzzy network DEA boils down to a conventional one. Third, to reduce the flexibility of weights and improve the discrimination of the DEA model, this study imposes weight restrictions on the proposed model.

This paper is organized as follows. In the next section, a conventional network DEA model is introduced. We propose a fuzzy network DEA decision-making model to calculate the fuzzy overall and DMs' efficiencies with multiple DMs and weight restrictions. An example is used to illustrate how we perform the AMT selection using the idea proposed in this paper. Finally, some conclusions are drawn based on the discussion.

\section{The Proposed Model}

\subsection{DEA with Multiple DMs}

Let $X_{i j}$ and $Y_{r j}$ denote the $i$ th input, $i=1, \ldots, m$, and $r$ th output, $r=1, \ldots, s$, respectively, of the $j$ th DMU, $j=1, \ldots, n$. The CCR model [33] of DEA for deriving the performance of DMU $k$ is

$$
\begin{aligned}
E_{k}^{C C R}=\max & \sum_{r=1}^{s} u_{r} Y_{r k} / \sum_{i=1}^{m} v_{i} X_{i k} \\
\text { s.t. } & \sum_{r=1}^{s} u_{r} Y_{r k} / \sum_{i=1}^{m} v_{i} X_{i k} \leq 1, j=1, \ldots, n, \\
& u_{r}, v_{i} \geq 0, r=1, \ldots, s, i=1, \ldots, m .
\end{aligned}
$$

where $u_{r}$ and $v_{i}$ are virtual multipliers.

Consider a decision-making system composed of a number of $h \mathrm{DMs}$, as shown in Figure 1, where the superscript $d$ in $X_{i j}^{(d)}$ and $Y_{r j}^{(d)}$ denotes the corresponding DM. For the decision-making system, if each DM is viewed as a process of a parallel network system, then it resembles the structure of a parallel network system with $h$ processes. The relational model proposed by Kao [34], as presented in Model (2), for measuring the efficiency of the 
parallel network system can thus be adopted to measure the efficiency of a decision-making system.

$$
\begin{aligned}
E_{k}=\max & \sum_{r=1}^{s} \sum_{d=1}^{h} u_{r} Y_{r k}^{(d)} \\
\text { s.t. } & \sum_{i=1}^{m} \sum_{d=1}^{h} v_{i} X_{i k}^{(d)}=1 \\
& \sum_{r=1}^{s} u_{r} Y_{r j}^{(d)}-\sum_{i=1}^{m} v_{i} X_{i j}^{(d)} \leq 0, d=1, \ldots, h, j=1, \ldots, n, \\
& u_{r}, v_{i} \geq 0, r=1, \ldots, s, i=1, \ldots, m .
\end{aligned}
$$

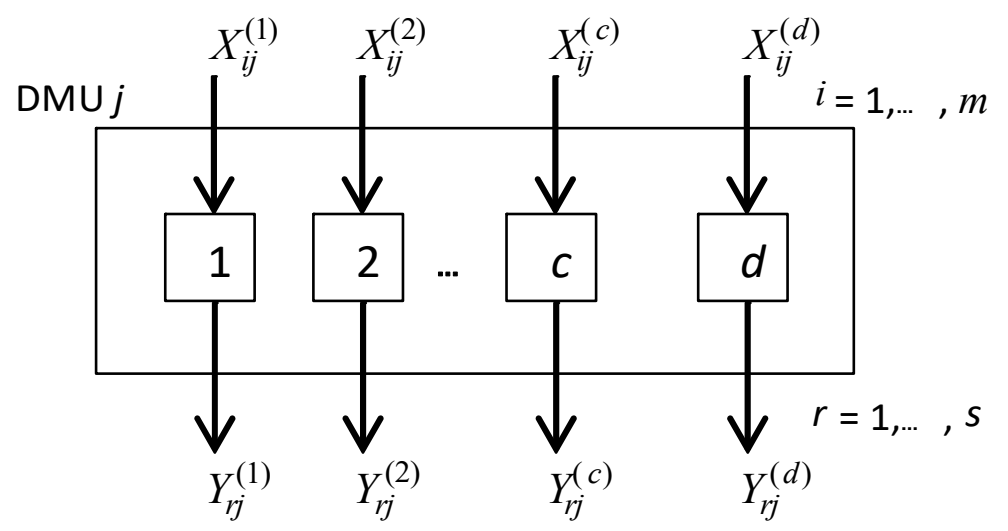

Figure 1. Structure of the decision-making system.

The constraints of Model (2) are those corresponding to $h$ DMs of $n$ alternatives and indicate that each DM is considered an independent reviewer for the evaluation in constructing the efficiency frontier. The objective is to find the multipliers that will produce the best overall efficiency for the alternative being evaluated.

After the optimal solutions $u_{r}^{*}$ and $v_{i}^{*}$ are obtained, the overall efficiency $E_{k}$, DM's efficiency $E_{k}^{(d)}$ and its associated weights $w^{(d)}, d=1, \ldots, h$, for Alternative $k$, are calculated as [34]:

$$
\begin{aligned}
& E_{k}=\sum_{d=1}^{h}\left(\frac{\sum_{r=1}^{s} u_{r}^{*} \gamma_{r k}^{(d)}}{\sum_{i=1}^{m} v_{i}^{*} X_{i k}}\right)=\frac{\sum_{r=1}^{s} u_{r}^{*} Y_{r k}}{\sum_{i=1}^{m} v_{i}^{*} X_{i k}}=\sum_{r=1}^{s} u_{r}^{*} Y_{r k} \\
& E_{k}^{(d)}=\frac{\sum_{r=1}^{s} u_{r}^{*} Y_{r k}^{(d)}}{\sum_{i=1}^{m} v_{i}^{*} X_{i k}^{(d)}}, d=1, \ldots, h, \\
& w^{(d)}=\frac{\sum_{i=1}^{m} v_{i}^{*} X_{i k}^{(d)}}{\sum_{i=1}^{m} v_{i}^{*} X_{i k}}, d=1, \ldots, h .
\end{aligned}
$$

The overall efficiency is the average of the $h$ DM efficiencies weighted by $w^{(d)}$ :

$$
\begin{aligned}
\sum_{d=1}^{h} w^{(d)} E_{k}^{(d)} & =\sum_{d=1}^{h}\left(\frac{\sum_{i=1}^{m} v_{i}^{*} X_{i k}^{(d)}}{\sum_{i=1}^{m} v_{i}^{*} X_{i k}^{*}} \times \frac{\sum_{r=1}^{s} u_{r}^{*} Y_{r k}^{(d)}}{\sum_{i=1}^{m} v_{i k}^{*}(d)}\right) \\
& =\sum_{d=1}^{h}\left(\frac{\sum_{r=1}^{s} u_{r}^{*} Y_{r k}^{(d) *}}{\sum_{i=1}^{m} v_{i}^{*} X_{i k}^{*}}\right)=\frac{\sum_{r=1}^{s} u_{r}^{*} Y_{r k}^{*}}{\sum_{i=1}^{m} v_{i}^{*} X_{i k}^{*}}=E_{k}
\end{aligned}
$$

In the next section, we shall develop a fuzzy decision-making model considering multiple DMs and weight restrictions in the DEA model.

\subsection{Fuzzy Network DEA in Decision-Making}

Allen et al. [35] classified weight restrictions on DEA models into three major categories, namely, absolute weight restriction, restricting virtual inputs and outputs, and assurance region. Absolute weight restrictions directly provide lower and upper bounds for input and output weights. This type of weight restriction was first introduced by 
Dyson and Thanassoulis [36]. Nevertheless, the difficulty is associated with DEA models' potential infeasibility with absolute weight restrictions [37]. The method of restrictions on virtual inputs and outputs was first investigated in Wong and Beasley [38]. The virtual inputs and outputs of a DMU disclose each input's relative contribution and output to its efficiency rating. However, as Thanassoulis et al. [39] pointed out, DEA models with such constraints may become computationally expensive and sensitive to the model orientation. The assurance region imposes relative lower bound and upper bound to incorporate value judgments in DEA models. This approach, first proposed by Thompson et al. [40], is originally developed with the purpose of incorporating value judgments into the analysis; that is, prior information, DM opinions, or preferences concerning the underlying process of assessing efficiency. Since then, such weight restrictions have been applied in various applications. Thompson et al. [41] pointed out that different oriented DEA models produce consistent results. The assurance region method shares similarity with assessing trade-offs in multi-criteria decision analysis [5]. Therefore, we adopt the assurance region approach to impose weight restrictions in this paper.

Suppose the relative importance elicited from the DMs range from $L_{I_{1}}$ to $U_{I_{1}}$ for input item 1 and from $L_{I_{2}}$ to $U_{I_{2}}$ for input item 2 . The associated constraints are $L_{I_{1}} / U_{I_{2}} \leq v_{1} / v_{2}$ $\leq U_{I_{1}} / L_{I_{2}}$. Generalizing to all inputs and outputs, respectively, gives

$$
\begin{gathered}
L_{I_{a}} / U_{I_{b}} \leq v_{a} / v_{b} \leq U_{I_{a}} / L_{I_{b}}, a<b=2, \cdots, m \\
L_{O_{a}} / U_{O_{b}} \leq u_{a} / u_{b} \leq U_{O_{a}} / L_{O_{b}}, a<b=2, \cdots, s
\end{gathered}
$$

To simplify the notation, let $F_{a b}^{L}=L_{I_{a}} / U_{I_{b}}, F_{a b}^{U}=U_{I_{a}} / L_{I_{b}}, G_{a b}^{L}=L_{O_{a}} / U_{O_{b}}$, and $G_{a b}^{U}=$ $U_{O_{a}} / L_{O_{b}}$. Including the assurance region in (2) gives the following mathematical form:

$$
\begin{aligned}
E_{k}=\max & \sum_{r=1}^{s} \sum_{d=1}^{h} u_{r} Y_{r k}^{(d)} \\
\text { s.t. } & \sum_{i=1}^{m} \sum_{d=1}^{h} v_{i} X_{i k}^{(d)}=1, \\
& \sum_{r=1}^{s} u_{r} Y_{r j}^{(d)}-\sum_{i=1}^{m} v_{i} X_{i j}^{(d)} \leq 0, d=1, \ldots, h, j=1, \ldots, n, \\
& -v_{a}+F_{a b}^{L} v_{b} \leq 0, v_{a}-F_{a b}^{U} v_{b} \leq 0, a<b=2, \ldots, m, \\
& -u_{a}+G_{a b}^{L} u_{b} \leq 0, u_{a}-G_{a b}^{U} u_{b} \leq 0, a<b=2, \cdots, s .
\end{aligned}
$$

This model is a decision-making DEA model with multiple DMs and weight restrictions.

When the input and output observations are fuzzy numbers in (5), Model (5) becomes a fuzzy decision-making DEA model, and the resulting efficiency scores will also be fuzzy numbers. Denote $\widetilde{X}_{i j}^{(d)}$ and $\widetilde{Y}_{r j}^{(d)}$, as the fuzzy counterparts of $X_{i j}^{(d)}$ and $Y_{r j}^{(d)}$, respectively, in the deterministic case. Conceptually, Model (5) for fuzzy observations can be formulated as

$$
\begin{aligned}
\widetilde{E}_{k}=\max & \sum_{r=1}^{s} \sum_{d=1}^{h} u_{r} \widetilde{Y}_{r k}^{(d)} \\
\text { s.t. } & \sum_{i=1}^{m} v_{i} \sum_{d=1}^{h} \widetilde{X}_{i k}^{(d)}=1, \\
& \sum_{r=1}^{s} u_{r} \widetilde{Y}_{r j}^{(d)}-\sum_{i=1}^{m} v_{i} \widetilde{X}_{i j}^{(d)} \leq 0, d=1, \ldots, h, j=1, \ldots, n, \\
& -v_{a}+F_{a b}^{L} v_{b} \leq 0, v_{a}-F_{a b}^{U} v_{b} \leq 0, a<b=2, \ldots, m, \\
& -u_{a}+G_{a b}^{L} u_{b} \leq 0, u_{a}-G_{a b}^{U} u_{b} \leq 0, a<b=2, \cdots, s .
\end{aligned}
$$

Saati and Memariani [42] proposed a procedure to find a common set of weights in the fuzzy DEA model. By assessing upper bounds on factor weights and compacting the resulting intervals, a common set of weights is determined. Liu [43] developed a methodology for a fuzzy two-stage DEA model considering weight restrictions when the input and output data are represented as fuzzy numbers. Nevertheless, both the methods 
of Saati and Memariani [42] and Liu [43] cannot be applied to measure the efficiency of alternatives under the case of multiple DMs decision-making.

The fuzzy set theory applications in DEA are usually classified into four categories: (1) the tolerance approach; (2) the $\alpha$-level based approach; (3) the fuzzy ranking approach; and (4) the possibility approach [25]. In the $\alpha$-level based approach, the main idea is to convert the fuzzy DEA model into a pair of parametric programs in order to find the lower and upper bounds of the $\alpha$-level of the membership functions of the efficiency scores. By enumerating the different $\alpha$-levels, the membership function of the efficiency scores can be approximated. Moreover, since convex fuzzy numbers can be represented as forms of $\alpha$-level sets, any convex fuzzy numbers can be used as fuzzy inputs and outputs in this approach. Due to this sound property, the $\alpha$-level approach is the most popular fuzzy DEA model. [25], and we use this approach to formulate the mathematical models proposed in this study. Denote $\left(X_{i j}^{(d)}\right)_{\alpha}=\left[\left(X_{i j}^{(d)}\right)_{\alpha^{\prime}}^{L}\left(X_{i j}^{(d)}\right)_{\alpha}^{U}\right]$ and $\left(Y_{r j}^{(d)}\right)_{\alpha}=\left[\left(Y_{r j}^{(d)}\right)_{\alpha^{\prime}}^{L},\left(Y_{r j}^{(d)}\right)_{\alpha}^{U}\right]$, as the $\alpha$-cuts of $\widetilde{X}_{i j}^{(d)}$ and $\widetilde{Y}_{r j}^{(d)}$, respectively. To find $\left(E_{k}\right)_{\alpha}=\left[\left(E_{k}\right)_{\alpha^{\prime}}^{L}\left(E_{k}\right)_{\alpha}^{U}\right]$, we have to search the lower and upper bounds of the $\alpha$-cut of $\widetilde{E}_{k}$.

The upper bound $\left(E_{k}\right)_{\alpha}^{U}$ is equal to $\max \left\{e \mid \mu_{\widetilde{E}_{k}}(e) \geq \alpha\right\}$, and the lower bound $\left(E_{k}\right)_{\alpha}^{L}$ is equal to $\min \left\{e \mid \mu_{\tilde{E}_{k}}(e) \geq \alpha\right\}$. In symbols, they can be expressed as

$$
\begin{aligned}
& \begin{array}{c}
\left(E_{k}\right)_{\alpha}^{U}=\max _{\left(X_{i j}^{(d)}\right)_{\alpha}^{L} \leq x_{i j}^{(d)} \leq\left(X_{i j}^{(d)}\right)^{U} E_{k} E_{k}(\mathbf{x}, \mathbf{y})} \\
\left(Y_{r j}^{(d)}\right)_{\alpha}^{L} \leq y_{r j}^{(d)} \leq\left(Y_{r j}^{(d)}\right)_{\alpha}^{U} \\
\forall i, r, d, j
\end{array} \\
& \begin{aligned}
\left(E_{k}\right)_{\alpha}^{L}= & \min _{\left(X_{i j}^{(d)}\right)_{\alpha}^{L} \leq x_{i j}^{(d)} \leq\left(X_{i j}^{(d)}\right)_{\alpha}^{U}}^{U} E_{k}(\mathbf{x}, \mathbf{y}) \\
& \left(Y_{r j}^{(d)}\right)_{\alpha}^{L} \leq y_{r j}^{(d)} \leq\left(Y_{r j}^{(d)}\right)_{\alpha}^{U} \\
& \forall i, r, d, j
\end{aligned}
\end{aligned}
$$

where $E_{k}(\mathbf{x}, \mathbf{y})$ is defined by Model (5). Note that $E_{k}(\mathbf{x}, \mathbf{y})$ is a mathematical program with maximization as the objective function. Therefore, Models (7) and (8) are two-level programs, with $E_{k}(\mathbf{x}, \mathbf{y})$ as the inner program. $\left(E_{k}\right)_{\alpha}^{U}$ and $\left(E_{k}\right)_{\alpha}^{L}$ can be calculated via the following two-level programming models:

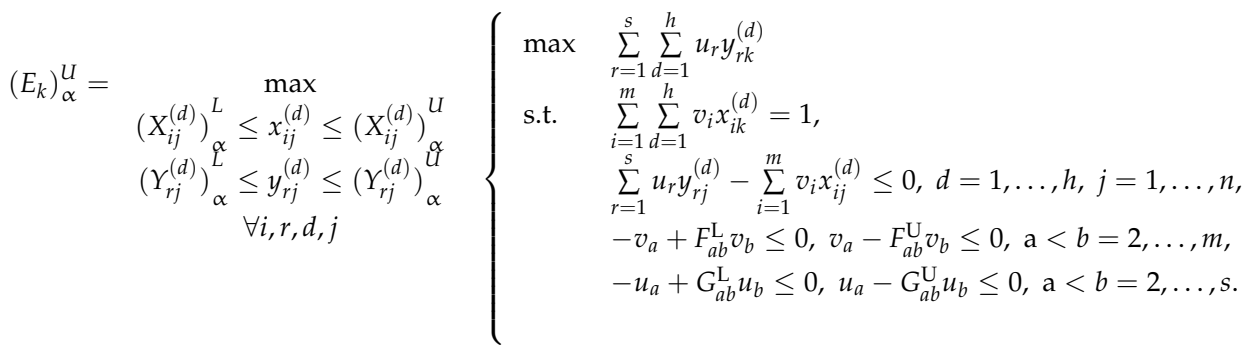

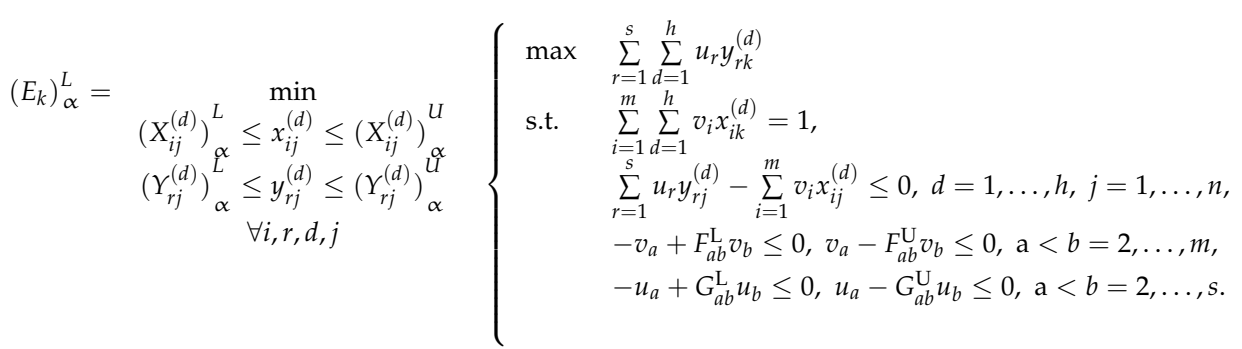


For each set of $x_{i j}^{(d)}$ and $y_{r j}^{(d)}$ values defined by the respective $\alpha$-levels in the outer program (first level), the evaluation-score is calculated in the inner program (second level). The sets of $x_{i j}^{(d)}$ and $y_{r j}^{(d)}$ values, which produce the largest and smallest evaluation-scores, are determined at the first level by Models (9) and (10), respectively.

The inner and outer programs of Model (9) have the same direction for optimization. Therefore, they can be combined into one level, with the objective function of the inner program as the objective function and the constraints at the two levels as the overall constraints, which yields:

$$
\begin{aligned}
\left(E_{k}\right)_{\alpha}^{U}= & \sum_{r=1}^{s} \sum_{d=1}^{h} u_{r} y_{r k}^{(d)} \\
\text { s.t. } & \sum_{i=1}^{m} \sum_{d=1}^{h} v_{i} x_{i k}^{(d)}=1, \\
& \sum_{r=1}^{s} u_{r} y_{r j}^{(d)}-\sum_{i=1}^{m} v_{i} x_{i j}^{(d)} \leq 0, d=1, \ldots, h, j=1, \ldots, n, \\
& \left(X_{i j}^{(d)}\right)_{\alpha}^{L} \leq x_{i j}^{(d)} \leq\left(X_{i j}^{(d)}\right)_{\alpha^{\prime}}^{U}, i=1, \ldots, m, d=1, \ldots, h, \\
& j=1, \ldots, n, \\
& \left(Y_{r j}^{(d)}\right)_{\alpha}^{L} \leq y_{r j}^{(d)} \leq\left(Y_{r j}^{(d)}\right)_{\alpha^{\prime}}^{U}, r=1, \ldots, s, d=1, \ldots, h, \\
& j=1, \ldots, n, \\
& -v_{a}+F_{a b}^{L} v_{b} \leq 0, v_{a}-F_{a b}^{U} v_{b} \leq 0, a<b=2, \ldots, m, \\
& -u_{a}+G_{a b}^{L} u_{b} \leq 0, u_{a}-G_{a b}^{U} u_{b} \leq 0, a<b=2, \ldots, s .
\end{aligned}
$$

This program is nonlinear due to the nonlinear terms $u_{r} y_{r j}^{(d)}$ and $v_{i} x_{i j}^{(d)}$. However, by substituting the former by $p_{r j}^{(d)}$ and the latter by $q_{i j}^{(d)}$, Model (11) can be transformed into the following linear program:

$$
\begin{aligned}
\left(E_{k}\right)_{\alpha}^{U}=\max & \sum_{r=1}^{s} \sum_{d=1}^{h} p_{r k}^{(d)} \\
\text { s.t. } \quad & \sum_{i=1}^{m} \sum_{d=1}^{h} q_{i k}^{(d)}=1, \\
& \sum_{r=1}^{s} p_{r j}^{(d)}-\sum_{i=1}^{m} q_{i j}^{(d)} \leq 0, \\
& \left(X_{i j}^{(d)}\right)_{\alpha}^{L} \leq x_{i j}^{(d)} \leq\left(X_{i j}^{(d)}\right)_{\alpha^{\prime}}^{U}, i=1, \ldots, m, d=1, \ldots, h, \\
& j=1, \ldots, n, \\
& \left(Y_{r j}^{(d)}\right)_{\alpha}^{L} \leq y_{r j}^{(d)} \leq\left(Y_{r j}^{(d)}\right)_{\alpha^{\prime}}^{U}, r=1, \ldots, s, d=1, \ldots, h, \\
& j=1, \ldots, n, \\
& -v_{a}+F_{a b}^{L} v_{b} \leq 0, v_{a}-F_{a b}^{U} v_{b} \leq 0, a<b=2, \ldots, m, \\
& -u_{a}+G_{a b}^{L} u_{b} \leq 0, u_{a}-G_{a b}^{U} u_{b} \leq 0, a<b=2, \ldots, s .
\end{aligned}
$$


After an optimal solution $\left(u_{r}^{*}, v_{i}^{*}, p_{r k}^{(d) *}, q_{i k}^{(d) *}\right)$ is obtained, we have $y_{r k}^{(d) *}=p_{r k}^{(d) *} / u_{r}^{*}$ and $x_{i k}^{(d) *}=q_{i k}^{(d) *} / v_{i}^{*}$. Let $X_{i k}^{*}=\sum_{d=1}^{h} x_{i k}^{(d) *}$ and $Y_{i k}^{*}=\sum_{d=1}^{h} y_{i k}^{(d) *}$. Then the overall and DM efficiency scores and the associated weights are calculated as

$$
\begin{aligned}
& \left(E_{k}\right)_{\alpha}^{U}=\frac{\sum_{r=1}^{s} \sum_{d=1}^{h} u_{r}^{*} y_{r k}^{(d) *}}{\sum_{i=1}^{m} \sum_{d=1}^{h} v_{i}^{*} x_{i k}^{(d) *}}=\frac{\sum_{r=1}^{s} u_{r}^{*} Y_{r k}^{*}}{\sum_{i=1}^{m} v_{i}^{*} X_{i k}^{*}}=\sum_{r=1}^{s} u_{r}^{*} Y_{r k}^{*} \\
& \left(E_{k}^{(d)}\right)_{\alpha}^{U}=\frac{\sum_{r=1}^{s} u_{r}^{*} y_{r k}^{(d) *}}{\sum_{i=1}^{m} v_{i}^{*} x_{i k}^{(d) *}}, d=1, \ldots, h, \\
& w_{k}^{(d)}=\frac{\sum_{i=1}^{m} v_{i}^{*} x_{i k}^{(d) *}}{\sum_{i=1}^{m} v_{i}^{*} X_{i k}^{*}}, d=1, \ldots, h .
\end{aligned}
$$

The overall efficiency $\left(E_{k}\right)_{\alpha}^{U}$ is the average of the DM efficiency $\left(E_{k}^{(d)}\right)_{\alpha}^{U}$ weighted by $w_{k}^{(d)}$ for all $\alpha$ values.

$$
\begin{aligned}
\sum_{d=1}^{h} w^{(d)}\left(E_{k}^{(d)}\right)_{\alpha}^{U} & =\sum_{d=1}^{h}\left(\frac{\sum_{i=1}^{m} v_{i}^{*} x_{i k}^{(d) *}}{\sum_{i=1}^{m} v_{i}^{*} X_{i k}^{*}} \times \frac{\sum_{r=1}^{s} u_{r}^{*} y_{r k}^{(d) *}}{\sum_{i=1}^{m} v_{i k}^{*}(d)}\right) \\
& =\sum_{d=1}^{h}\left(\frac{\sum_{r=1}^{S} u_{r}^{*} y_{r k *}^{(d)}}{\sum_{i=1}^{m} v_{i}^{*} X_{i k}^{*}}\right)=\frac{\sum_{r=1}^{s} u_{r}^{*} Y_{r k}^{*}}{\sum_{i=1}^{m} v_{i}^{*} X_{i k}^{*}}=\left(E_{k}\right)_{\alpha}^{U}
\end{aligned}
$$

The transformation of Model (10) into a one-level program is not so straightforward because the directions of optimization for the inner and outer programs are different. The inner program is a linear program when the values $x_{i j}^{(d)}$ and $y_{r j}^{(d)}$ are assigned by the outer program. According to the duality theorem [44], the primal and dual programs have the same objective value at optimality. Hence, the inner program can be replaced by its dual to change the objective function from maximization to minimization. The dual form of the inner program of (10) can be formulated as

$$
\begin{array}{ll}
\min & \theta \\
\text { s.t. } & \theta \sum_{d=1}^{h} x_{i k}^{(d)}-\sum_{d=1}^{h} \sum_{j=1}^{n} \lambda_{j}^{(d)} x_{i j}^{(d)}+\sum_{b>i}\left(-\alpha_{i b}^{L}+\alpha_{i b}^{U}\right)+\sum_{a<i}\left(\alpha_{a i}^{L} F_{a i}^{L}-\alpha_{a i}^{U} I_{a i}^{U}\right)-s_{i}^{+}=0, \\
& i=1, \cdots, m, \\
& \sum_{d=1}^{h} \sum_{j=1}^{n} \lambda_{j}^{(d)} y_{r j}^{(d)}+\sum_{b>r}\left(-\beta_{r b}^{L}+\beta_{r b}^{U}\right)+\sum_{a<r}\left(\beta_{a r}^{L} G_{a r}^{L}-\beta_{a r}^{U} G_{a r}^{U}\right)-s_{r}^{-}=\sum_{d=1}^{h} y_{r k}^{(d)}, \\
& r=1, \cdots, s, \\
& \lambda_{j}^{(d)}, s_{i}^{+}, s_{r}^{-} \geq 0, i=1, \ldots, m, r=1, \ldots, s, d=1, \ldots, h, j=1, \ldots, n, \\
& \theta \text { unrestricted in sign. }
\end{array}
$$


After this replacement, both the inner and outer programs have the same direction of minimization; thus, they can be combined into the same one level. The resulting program of (10) becomes the following one-level program:

$$
\begin{aligned}
& \left(E_{k}\right)_{\alpha}^{L}=\min \theta \\
& \text { s.t. } \theta \sum_{d=1}^{h} x_{i k}^{(d)}-\sum_{d=1}^{h} \sum_{j=1}^{n} \lambda_{j}^{(d)} x_{i j}^{(d)}+\sum_{b>i}\left(-\alpha_{i b}^{L}+\alpha_{i b}^{U}\right)+\sum_{a<i}\left(\alpha_{a i}^{L} F_{a i}^{L}-\alpha_{a i}^{U} F_{a i}^{U}\right)-s_{i}^{+}=0, \\
& i=1, \ldots, m, \\
& \quad \sum_{d=1}^{h} \sum_{j=1}^{n} \lambda_{j}^{(d)} y_{r j}^{(d)}+\sum_{b>r}\left(-\beta_{r b}^{L}+\beta_{r b}^{U}\right)+\sum_{a<r}\left(\beta_{a r}^{L} G_{a r}^{L}-\beta_{a r}^{U} G_{a r}^{U}\right)-s_{r}^{-}=\sum_{d=1}^{h} y_{r k}^{(d)}, \\
& \quad r=1, \ldots, s, \\
& \quad\left(X_{i j}^{(d)}\right)^{L} \leq x_{i j}^{(d)} \leq\left(X_{i j}^{(d)}\right)^{U}{ }^{\prime}{ }^{\prime} i=1, \ldots, m, d=1, \ldots, h, j=1, \ldots, n, \\
& \quad\left(Y_{r j}^{(d)}\right)_{\alpha}^{L} \leq y_{r j}^{(d)} \leq\left(Y_{r j}^{(d)}\right)_{\alpha^{\prime}}{ }^{\prime} r=1, \ldots, s, d=1, \ldots, h, j=1, \ldots, n, \\
& \lambda_{j}^{(d)}, s_{i}^{+}, s_{r}^{-} \geq 0, i=1, \ldots, m, r=1, \ldots, s, d=1, \ldots, h, j=1, \ldots, n, \\
& \quad \theta \text { unrestricted in sign. }
\end{aligned}
$$

This program is nonlinear due to the nonlinear terms $\lambda_{j}^{(d)} x_{i j}^{(d)}$ and $\lambda_{j}^{(d)} y_{r j}^{(d)}$, and these cannot be linearized by variable substitutions, as occurs in (11). Since this program has only $m+s$ nonlinear constraints, which is of small size in the standard of nonlinear programming, most commercial nonlinear-program solvers can be used to derive a solution.

The objective value of (16) is just the lower bound of the overall efficiency at the $\alpha$ level, $\left(E_{k}\right)_{\alpha}^{L}$. At optimality, the reduced costs of $s_{i}^{+}$and $s_{r}^{-}$are the values of multipliers $v_{i}$ and $u_{r}$, respectively, of the primal program. The overall efficiency, the efficiency of all DMs, and the corresponding weights subsequently yield

$$
\begin{aligned}
& \left(E_{k}\right)_{\alpha}^{L}=\frac{\sum_{r=1}^{s} \sum_{d=1}^{h} u_{r}^{*} y_{r k}^{(d) *}}{\sum_{i=1}^{m} \sum_{d=1}^{h} v_{i}^{*} x_{i k}^{(d) *}}=\frac{\sum_{r=1}^{s} u_{r}^{*} Y_{r k}^{*}}{\sum_{i=1}^{m} v_{i}^{*} X_{i k}^{*}}=\sum_{r=1}^{s} u_{r}^{*} Y_{r k}^{*} \\
& \left(E_{k}^{(d)}\right)_{\alpha}^{L}=\frac{\sum_{r=1}^{s} u_{r}^{*} y_{r k}^{(d) *}}{\sum_{i=1}^{m} v_{i}^{*} x_{i k}^{(d) *}}, d=1, \ldots, h, \\
& w_{k}^{(d)}=\frac{\sum_{i=1}^{m} v_{i}^{*} x_{i k}^{(d) *}}{\sum_{i=1}^{m} v_{i}^{*} X_{i k}^{*}}, d=1, \ldots, h .
\end{aligned}
$$

Similar to the upper-bound case, $\left(E_{k}\right)_{\alpha}^{L}$ is the average of $\left(E_{k}^{(d)}\right)_{\alpha}^{L}$ weighted by $w_{k}^{(d)}$ for all $\alpha$ values.

$$
\begin{aligned}
\sum_{d=1}^{h} w^{(d)}\left(E_{k}^{(d)}\right)_{\alpha}^{L} & =\sum_{d=1}^{h}\left(\frac{\sum_{i=1}^{m} v_{i k}^{*} x_{i k}^{(d) *}}{\sum_{i=1}^{m} v_{i}^{*} X_{i k}^{*}} \times \frac{\sum_{r=1}^{s} u_{r}^{*} y_{r k}^{(d) *}}{\sum_{i=1}^{m} v_{i k}^{*}(d)}\right) \\
& =\sum_{d=1}^{h}\left(\frac{\sum_{r=1}^{s} u_{r}^{*} y_{r k}^{(d) *}}{\sum_{i=1}^{m} v_{i}^{*} X_{i k}^{*}}\right)=\frac{\sum_{r=1}^{s} u_{r}^{*} Y_{r k}^{*}}{\sum_{i=1}^{m} v_{i}^{*} X_{i k}^{*}}\left(E_{k}\right)_{\alpha}^{L}
\end{aligned}
$$

Note that the set of weights selected by each alternative is the most advantageous one to calculate the overall efficiency, and they may not be the same for all alternatives. Equations (14) and (18) are thus able to not only calculate the overall and DM efficiency scores of the multiple DMs decision-making but also obtain a mathematical relationship between them.

Together with the upper bound of the overall efficiency derived from (12), the upper bound and lower bound of the fuzzy overall efficiency at a specific $\alpha$-level are obtained. Enumerating various values of $\alpha$, the membership function of $\widetilde{E}_{k}$ can be approximated numerically. 


\subsection{Fuzzy Efficiency Ranking}

Since the obtained efficiency scores are fuzzy numbers, the ranking of these scores still remains to be determined. In the literature, there are some methods for ranking fuzzy numbers [45-50]. Most of the existing methods are based on area measurement or the corresponding integral values that require the exact forms of the fuzzy numbers membership functions to be ranked. They can hardly be applied if the membership functions of the fuzzy numbers are not explicitly known [18]. The method of Chen and Klein [45], which does not need the exact membership functions of the fuzzy numbers to be ranked, is a proper method for this study. The method of Chen and Klein [45] devised the following index for ranking fuzzy numbers:

$$
I\left(\widetilde{E}_{j}\right)=\frac{\sum_{i=0}^{\infty}\left(\left(E_{j}\right)_{\alpha_{i}}^{U}-\beta\right)}{\left[\sum_{i=0}^{\infty}\left(\left(E_{j}\right)_{\alpha_{i}}^{U}-\beta\right)-\sum_{i=0}^{\infty}\left(\left(E_{j}\right)_{\alpha_{i}}^{L}-\gamma\right)\right]}
$$

where $\beta=\min _{i, j}\left\{\left(E_{j}\right)_{\alpha_{i}}^{L}\right\}$ and $\gamma=\max _{i, j}\left\{\left(E_{j}\right)_{\alpha_{i}}^{U}\right\}$. Let $I\left(E_{j}^{L}\right)=\sum_{i=0}^{\infty}\left(\left(E_{j}\right)_{\alpha_{i}}^{L}-\gamma\right)$ and $I\left(E_{j}^{U}\right)=$ $\sum_{i=0}^{\infty}\left(\left(E_{j}\right)_{\alpha_{i}}^{U}-\beta\right)$, and Equation (19) can be rewritten as

$$
I\left(\widetilde{E}_{j}\right)=\frac{I\left(E_{j}^{U}\right)}{I\left(E_{j}^{U}\right)-I\left(E_{j}^{L}\right)}
$$

The larger the value of the ranking index $I\left(\widetilde{E}_{j}\right)$, the larger the number is. According to the ranking indices, the overall efficiency of the evaluated alternatives are ranked accordingly.

\section{Example}

In this example, we revise Liu's data [13], where are used to measure twelve flexible manufacturing system (FMS) alternatives performance, to illustrate the idea proposed in this paper. Two inputs and four outputs are applied to compare the FMS candidates. The input items include capital and operating costs, which are measured in units of one hundred thousand dollars, and floor space requirements, which are measured in thousands of square feet. The output measures include the improvements in qualitative factors, workin-process (WIP), numbers of tardy jobs, and yield. Yield is defined as throughput minus scrape and rework.

Suppose that a committee of three DMs, who are senior engineering specialists, namely, $D_{1}, D_{2}$, and $D_{3}$, has been constituted to discuss and determine the required input and output factors for the assessment of FMS alternatives and select the most suitable one among the alternatives. The revised data set from Liu [13], as shown in Table 1, is used to measure the fuzzy efficiency scores of the twelve FMS alternatives. Among the input and output factors, some factors are not known beforehand, and they need to be estimated. One approach used in the absence of data is to ask the experts for their subjective estimates of the values and represent them as triangular fuzzy numbers. For example, the total cost includes the estimated operation and maintenance costs and can therefore be constructed from the pessimistic, optimistic, and most possible estimates solicited from the experts, to express its uncertainty. This situation also occurs in the factors of WIP, number of tardy jobs, and yields. On the other hand, the space and improvements in the qualitative factors are the specifications of the AMTs provided by suppliers, and they are crisp values. In this case, it is not too difficult or time-consuming for the experts to estimate the factors' values. The associated weight restrictions imposed on Models (12) and (16) are the same as those represented in Liu [13]. That is, the relative importance of cost is $v_{1}=[0.7500$, 0.8333], on a scale of 1.0. Similar to the total cost, the floor space is determined in the range of $v_{2}=[0.1667,0.2500]$. For the output items, namely, qualitative factor, WIP, numbers of 
tardy jobs, and yield, they lie in the ranges of, $u_{1}=[0.4023,0.4667], u_{2}=[0.0795,0.1361]$, $u_{3}=[0.1392,0.1850]$, and $u_{4}=[0.2766,0.3146]$, respectively. Based on Equation (4), the AR generated for the multipliers of input items is

$$
\frac{0.7500}{0.2500} \leq \frac{v_{1}}{v_{2}} \leq \frac{0.8333}{0.1667}
$$

Table 1. Input and output data for the twelve FMS alternatives.

\begin{tabular}{|c|c|c|c|c|c|c|c|}
\hline \multirow[b]{2}{*}{ FMS } & \multirow[b]{2}{*}{ DM } & \multicolumn{2}{|l|}{ Inputs } & \multicolumn{4}{|c|}{ Outputs } \\
\hline & & Total Cost & Space & Quali. & WIP & No. of Tardy & Yield \\
\hline \multirow[t]{3}{*}{1} & 1 & $(16.17,17.02,17.87)$ & 5 & 42 & $(43.01,45.30,47.60)$ & $(13.50,14.20,14.90)$ & $(28.60,30.10,31.60)$ \\
\hline & 2 & $(18.02,18.97,19.92)$ & 5 & 42 & $(47.92,50.49,53.05)$ & $(15.05,15.83,16.61)$ & $(31.87,33.55,35.22)$ \\
\hline & 3 & $(16.13,16.98,17.83)$ & 5 & 42 & $(42.91,45.20,47.50)$ & $(14.17,14.87,28.54)$ & $(28.54,30.03,31.53)$ \\
\hline \multirow[t]{3}{*}{2} & 1 & $(15.64,16.46,17.28)$ & 4.5 & 39 & $(38.10,40.10,42.10)$ & $(12.40,13.00,13.70)$ & $(28.30,29.80,31.30)$ \\
\hline & 2 & $(15.37,16.17,16.98)$ & 4.5 & 39 & $(37.43,39.40,41.36)$ & $(12.18,12.77,13.46)$ & $(27.80,29.28,30.75)$ \\
\hline & 3 & $(16.47,17.33,18.20)$ & 4.5 & 39 & $(40.12,42.23,44.33)$ & $(13.06,13.69,14.43)$ & $(29.80,31.38,32.96)$ \\
\hline \multirow[t]{3}{*}{3} & 1 & $(11.17,11.76,12.35)$ & 6 & 26 & $(37.60,39.60,41.60)$ & $(13.10,13.80,14.50)$ & $(23.30,24.50,25.70)$ \\
\hline & 2 & $(10.81,11.38,11.95)$ & 6 & 26 & $(36.39,38.32,40.26)$ & $(12.68,13.36,14.03)$ & $(22.55,23.71,24.87)$ \\
\hline & 3 & $(10.44,10.99,11.54)$ & 6 & 26 & $(35.14,37.01,38.88)$ & $(12.24,12.90,13.55)$ & $(21.77,22.90,24.02)$ \\
\hline \multirow[t]{3}{*}{4} & 1 & $(9.99,10.52,11.05)$ & 4 & 22 & $(34.20,36.00,37.80)$ & $(10.70,11.30,11.90)$ & $(23.80,25.00,26.30)$ \\
\hline & 2 & $(10.63,11.20,11.76)$ & 4 & 22 & $(36.40,38.31,40.23)$ & $(11.39,12.03,12.67)$ & $(25.33,26.61,27.99)$ \\
\hline & 3 & $(10.98,11.56,12.14)$ & 4 & 22 & $(37.58,39.56,41.54)$ & $(11.76,12.42,13.08)$ & $(26.15,27.47,28.90)$ \\
\hline \multirow[t]{3}{*}{5} & 1 & $(9.03,9.50,9.98)$ & 3.8 & 21 & $(32.50,34.20,35.90)$ & $(11.40,12.00,12.60)$ & $(19.40,20.40,21.40)$ \\
\hline & 2 & $(10.63,11.20,11.76)$ & 3.8 & 21 & $(36.40,38.31,40.23)$ & $(11.39,12.03,12.67)$ & $(25.33,26.61,27.99)$ \\
\hline & 3 & $(8.90,9.36,9.84)$ & 3.8 & 21 & $(32.03,33.70,35.38)$ & $(11.23,11.83,12.42)$ & $(19.12,20.10,21.09)$ \\
\hline \multirow[t]{3}{*}{6} & 1 & $(4.55,4.79,5.03)$ & 5.4 & 10 & $(19.10,20.10,21.10)$ & $(4.80,5.00,5.30)$ & $(15.70,16.50,17.30)$ \\
\hline & 2 & $(4.89,5.15,5.41)$ & 5.4 & 10 & $(20.54,21.62,22.69)$ & $(5.16,5.38,5.70)$ & $(16.88,17.74,18.60)$ \\
\hline & 3 & $(4.89,5.15,5.41)$ & 5.4 & 10 & $(20.54,21.62,22.69)$ & $(5.16,5.38,5.70)$ & $(16.88,17.74,18.60)$ \\
\hline \multirow[t]{3}{*}{7} & 1 & $(4.55,4.79,5.03)$ & 6.2 & 14 & $(25.20,26.50,27.80)$ & $(6.70,7.00,7.40)$ & $(18.70,19.70,20.70)$ \\
\hline & 2 & $(6.76,7.11,7.47)$ & 6.2 & 14 & $(28.86,30.35,31.84)$ & $(7.67,8.02,8.47)$ & $(21.42,22.56,23.71)$ \\
\hline & 3 & $(5.83,6.13,6.44)$ & 6.2 & 14 & $(24.89,26.18,27.46)$ & $(6.62,6.91,7.31)$ & $(18.47,19.46,20.45)$ \\
\hline \multirow[t]{3}{*}{8} & 1 & $(10.56,11.12,11.68)$ & 6 & 25 & $(34.10,35.90,37.70)$ & $(8.60,9.00,9.50)$ & $(23.50,24.70,25.90)$ \\
\hline & 2 & $(10.41,10.96,11.51)$ & 6 & 25 & $(33.60,35.38,37.15)$ & $(8.47,8.87,9.36)$ & $(23.16,24.34,25.52)$ \\
\hline & 3 & $(10.19,10.73,11.27)$ & 6 & 25 & $(32.89,34.63,36.36)$ & $(8.29,8.68,9.16)$ & $(22.67,23.82,24.98)$ \\
\hline \multirow[t]{3}{*}{9} & 1 & $(3.49,3.67,3.85)$ & 8 & 4 & $(16.50,17.40,18.30)$ & $(0.10,0.10,0.10)$ & $(17.20,18.10,19.00)$ \\
\hline & 2 & $(3.41,3.58,3.76)$ & 8 & 4 & $(16.11,16.99,17.87)$ & $(0.10,0.10,0.10)$ & $(16.80,17.67,18.55)$ \\
\hline & 3 & $(3.99,4.19,4.40)$ & 8 & 4 & $(18.85,19.88,20.91)$ & $(0.10,0.10,0.10)$ & $(19.65,20.68,21.71)$ \\
\hline \multirow[t]{3}{*}{10} & 1 & $(8.48,8.93,9.38)$ & 7 & 16 & $(32.60,34.30,36.00)$ & $(6.20,6.50,6.80)$ & $(19.60,20.60,21.60)$ \\
\hline & 2 & $(9.09,9.58,10.06)$ & 7 & 16 & $(34.96,36.79,38.61)$ & $(6.65,6.97,7.29)$ & $(21.02,22.09,23.17)$ \\
\hline & 3 & $(8.81,9.28,9.74)$ & 7 & 16 & $(33.86,35.63,37.40)$ & $(6.44,6.75,7.06)$ & $(20.36,21.40,22.44)$ \\
\hline \multirow[t]{3}{*}{11} & 1 & $(16.85,17.74,18.63)$ & 7.1 & 43 & $(43.30,45.60,47.90)$ & $(13.30,14.00,14.70)$ & $(29.50,31.10,32.70)$ \\
\hline & 2 & $(16.62,17.50,18.38)$ & 7.1 & 43 & $(42.72,44.99,47.26)$ & $(13.12,13.81,14.50)$ & $(29.10,30.68,32.26)$ \\
\hline & 3 & $(17.62,18.55,19.48)$ & 7.1 & 43 & $(45.28,47.68,50.09)$ & $(13.91,14.64,15.37)$ & $(30.85,32.52,34.19)$ \\
\hline \multirow[t]{3}{*}{12} & 1 & $(14.11,14.85,15.39)$ & 6.2 & 27 & $(36.80,38.70,40.60)$ & $(13.10,13.80,14.50)$ & $(24.10,25.40,26.70)$ \\
\hline & 2 & $(14.75,15.53,16.30)$ & 6.2 & 27 & $(38.48,40.47,42.46)$ & $(13.70,14.43,15.16)$ & $(25.20,26.56,27.92)$ \\
\hline & 3 & $(14.91,15.69,16.48)$ & 6.2 & 27 & $(38.89,40.90,42.91)$ & $(13.84,14.58,15.32)$ & $(25.47,26.84,28.22)$ \\
\hline
\end{tabular}

Similarly, the AR generated for the multipliers of input items are:

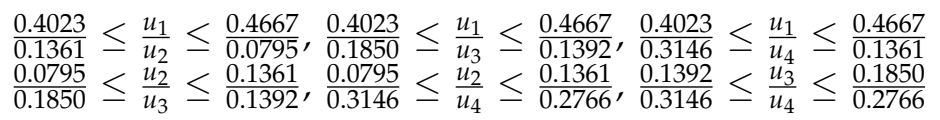


According to (12) and (16), the data contained in Table 1 are used to measure the lower bounds and upper bounds of the fuzzy overall efficiency $\widetilde{E}_{k}$ and the three DMs' efficiency scores $\widetilde{E}_{k}^{(d)}, d=1, \ldots, 3$, of the 12 FMS systems, respectively. For $\alpha$-level $=0,0.1,0.2, \ldots$, 1.0, Table 2 lists the lower bound $\left(E_{k}\right)_{\alpha}^{L}$ and upper bound $\left(E_{k}\right)_{\alpha}^{U}$ of the overall efficiency, associated with the lower bound $\left(E_{k}^{(d)}\right)_{\alpha}^{L}$ and upper bound $\left(E_{k}^{(d)}\right)_{\alpha^{\prime}}^{U} d=1, \ldots, 3$, of the three DMs' efficiency scores. Clearly, the obtained fuzzy efficiency scores vary in ranges, and the different value of $\alpha$-level indicates that the width interval of the efficiency. Moreover, the $\alpha$-level $=1.0$ shows the range that the obtained efficiency will appear; on the other hand, the $\alpha$-level $=1.0$ means that the obtained efficiency is most likely to be. For example, while the overall efficiency of FMS alternative No. 9 is fuzzy, its efficiency lies between the lower bound $0.719\left(\left(E_{9}\right)_{\alpha=0}^{L}\right)$ and the upper bound $0.972\left(\left(E_{9}\right)_{\alpha=0}^{U}\right)$. At the other end of $\alpha=1$, the single value of 0.837 , that is, $\left(E_{9}\right)_{\alpha=1}^{L}=\left(E_{9}\right)_{\alpha=1}^{U}$, shows that this value is the possible efficiency score of this FMS alternative. Similarly, the lower bound efficiency $\left(E_{9}^{(1)}\right)_{\alpha=0}^{L}$ and the upper bound efficiency $\left(E_{9}^{(1)}\right)_{\alpha=0}^{U}$ of DM No. 1 of this FMS alternative are 0.715 and 0.967 , respectively, and the possible efficiency of this $\operatorname{DM}\left(E_{9}^{(1)}\right)_{\alpha=1}^{L}=\left(E_{9}^{(1)}\right)_{\alpha=1}^{U}=0.832$. Note that the values in parentheses are the associated weights of the efficiencies.

Table 2. The lower bound and upper bound of the overall efficiency and (decision-makers) DMs' efficiencies for the twelve FMS alternatives at eleven distinctive $\alpha$-levels.

\begin{tabular}{|c|c|c|c|c|c|c|c|c|c|}
\hline FMS & $\alpha$ & $\left(E_{k}\right)_{\alpha}^{L}$ & $\left(E_{k}^{(1)}\right)_{\alpha}^{L}$ & $\left(E_{k}^{(2)}\right)_{\alpha}^{L}$ & $\left(E_{k}^{(3)}\right)_{\alpha}^{L}$ & $\left(E_{k}\right)_{\alpha}^{U}$ & $\left(E_{k}^{(1)}\right)_{\alpha}^{U}$ & $\left(E_{k}^{(2)}\right)_{\alpha}^{U}$ & $\left(E_{k}^{(3)}\right)_{\alpha}^{U}$ \\
\hline \multirow[t]{11}{*}{1} & 0.0 & 0.857 & $0.876(0.322)$ & $0.822(0.356)$ & $0.872(0.322)$ & 1.000 & $1.000(0.329)$ & $1.000(0.342)$ & $1.000(0.329)$ \\
\hline & 0.1 & 0.863 & $0.881(0.322)$ & $0.827(0.356)$ & $0.883(0.322)$ & 1.000 & $1.000(0.329)$ & $1.000(0.342)$ & $1.000(0.329)$ \\
\hline & 0.2 & 0.879 & $0.898(0.322)$ & $0.843(0.356)$ & $0.900(0.322)$ & 1.000 & $1.000(0.323)$ & $1.000(0.345)$ & $1.000(0.332)$ \\
\hline & 0.3 & 0.885 & $0.904(0.322)$ & $0.849(0.356)$ & $0.905(0.322)$ & 1.000 & $1.000(0.323)$ & $1.000(0.346)$ & $1.000(0.331)$ \\
\hline & 0.4 & 0.896 & $0.915(0.322)$ & $0.860(0.356)$ & $0.917(0.322)$ & 1.000 & $1.000(0.327)$ & $1.000(0.344)$ & $1.000(0.329)$ \\
\hline & 0.5 & 0.913 & $0.933(0.322)$ & $0.876(0.356)$ & $0.934(0.322)$ & 0.997 & $1.000(0.328)$ & $0.990(0.345)$ & $1.000(0.327)$ \\
\hline & 0.6 & 0.925 & $0.945(0.322)$ & $0.888(0.356)$ & $0.946(0.322)$ & 0.992 & $1.000(0.326)$ & $0.977(0.348)$ & $1.000(0.326)$ \\
\hline & 0.7 & 0.931 & $0.951(0.322)$ & $0.893(0.356)$ & $0.952(0.322)$ & 0.988 & $1.000(0.325)$ & $0.965(0.350)$ & $1.000(0.325)$ \\
\hline & 0.8 & 0.943 & $0.963(0.322)$ & $0.905(0.356)$ & $0.964(0.322)$ & 0.983 & $1.000(0.324)$ & $0.952(0.353)$ & $1.000(0.323)$ \\
\hline & 0.9 & 0.955 & $0.975(0.322)$ & $0.916(0.356)$ & $0.976(0.322)$ & 0.979 & $1.000(0.322)$ & $0.940(0.356)$ & $1.000(0.322)$ \\
\hline & 1.0 & 0.967 & $0.988(0.322)$ & $0.928(0.356)$ & $0.989(0.322)$ & 0.967 & $0.988(0.322)$ & $0.928(0.356)$ & $0.989(0.322)$ \\
\hline \multirow[t]{11}{*}{2} & 0.0 & 0.837 & $0.843(0.330)$ & $0.852(0.324)$ & $0.818(0.346)$ & 1.000 & $1.000(0.332)$ & $1.000(0.330)$ & $1.000(0.322)$ \\
\hline & 0.1 & 0.848 & $0.854(0.330)$ & $0.863(0.324)$ & $0.828(0.346)$ & 1.000 & $1.000(0.332)$ & $1.000(0.330)$ & $1.000(0.322)$ \\
\hline & 0.2 & 0.859 & $0.865(0.330)$ & $0.874(0.324)$ & $0.839(0.346)$ & 1.000 & $1.000(0.332)$ & $1.000(0.330)$ & $1.000(0.322)$ \\
\hline & 0.3 & 0.870 & $0.876(0.330)$ & $0.885(0.324)$ & $0.849(0.346)$ & 1.000 & $1.000(0.329)$ & $1.000(0.327)$ & $1.000(0.344)$ \\
\hline & 0.4 & 0.881 & $0.887(0.330)$ & $0.896(0.324)$ & $0.860(0.346)$ & 1.000 & $1.000(0.332)$ & $1.000(0.329)$ & $1.000(0.339)$ \\
\hline & 0.5 & 0.892 & $0.898(0.330)$ & $0.907(0.324)$ & $0.871(0.346)$ & 0.997 & $1.000(0.331)$ & $1.000(0.329)$ & $0.990(0.340)$ \\
\hline & 0.6 & 0903 & $0.909(0.330)$ & $0.919(0.324)$ & $0.882(0.346)$ & 0.992 & $1.000(0.329)$ & $1.000(0.328)$ & $0.977(0.343)$ \\
\hline & 0.7 & 0.915 & $0.921(0.330)$ & $0.931(0.324)$ & $0.894(0.346)$ & 0.986 & $0.994(0.329)$ & $1.000(0.326)$ & $0.965(0.345)$ \\
\hline & 0.8 & 0.926 & $0.933(0.330)$ & $0.942(0.324)$ & $0.905(0.346)$ & 0.975 & $0.981(0.330)$ & $0.991(0.324)$ & $0.953(0.346)$ \\
\hline & 0.9 & 0.938 & $0.945(0.330)$ & $0.954(0.324)$ & $0.917(0.346)$ & 0.962 & $0.969(0.330)$ & $0.979(0.324)$ & $0.940(0.346)$ \\
\hline & 1.0 & 0.950 & $0.957(0.330)$ & $0.966(0.324)$ & $0.928(0.346)$ & 0.950 & $0.957(0.330)$ & $0.967(0.324)$ & $0.928(0.346)$ \\
\hline \multirow[t]{11}{*}{3} & 0.0 & 0.848 & $0.833(0.344)$ & $0.847(0.333)$ & $0.863(0.323)$ & 1.000 & $1.000(0.339)$ & $1.000(0.333)$ & $1.000(0.328)$ \\
\hline & 0.1 & 0.859 & $0.844(0.344)$ & $0.859(0.333)$ & $0.874(0.323)$ & 1.000 & $1.000(0.338)$ & $1.000(0.333)$ & $1.000(0.329)$ \\
\hline & 0.2 & 0.870 & $0.856(0.344)$ & $0.870(0.333)$ & $0.886(0.323)$ & 1.000 & $1.000(0.338)$ & $1.000(0.333)$ & $1.000(0.329)$ \\
\hline & 0.3 & 0.882 & $0.867(0.344)$ & $0.882(0.333)$ & $0.898(0.323)$ & 1.000 & $1.000(0.341)$ & $1.000(0.330)$ & $1.000(0.329)$ \\
\hline & 0.4 & 0.894 & $0.879(0.344)$ & $0.893(0.333)$ & $0.910(0.323)$ & 1.000 & $1.000(0.341)$ & $1.000(0.330)$ & $1.000(0.329)$ \\
\hline & 0.5 & 0.905 & $0.890(0.344)$ & $0.905(0.333)$ & $0.922(0.323)$ & 1.000 & $1.000(0.337)$ & $1.000(0.334)$ & $1.000(0.329)$ \\
\hline & 0.6 & 0.917 & $0.902(0.344)$ & $0.917(0.333)$ & $0.934(0.323)$ & 1.000 & $1.000(0.341)$ & $1.000(0.332)$ & $1.000(0.327)$ \\
\hline & 0.7 & 0.930 & $0.914(0.344)$ & $0.929(0.333)$ & $0.946(0.323)$ & 0.997 & $0.993(0.340)$ & $1.000(0.332)$ & $1.000(0.328)$ \\
\hline & 0.8 & 0.942 & $0.926(0.344)$ & $0.942(0.333)$ & $0.959(0.323)$ & 0.990 & $0.977(0.342)$ & $0.993(0.332)$ & $1.000(0.326)$ \\
\hline & 0.9 & 0.954 & $0.939(0.344)$ & $0.954(0.333)$ & $0.971(0.323)$ & 0.980 & $0.964(0.344)$ & $0.980(0.333)$ & $0.997(0.323)$ \\
\hline & 1.0 & 0.967 & $0.951(0.344)$ & $0.967(0.333)$ & $0.984(0.323)$ & 0.967 & $0.951(0.344)$ & $0.967(0.333)$ & $0.984(0.323)$ \\
\hline \multirow[t]{6}{*}{4} & 0.0 & 0.845 & $0.860(0.318)$ & $0.842(0.336)$ & $0.834(0.346)$ & 1.000 & $1.000(0.322)$ & $1.000(0.335)$ & $1.000(0.343)$ \\
\hline & 0.1 & 0.857 & $0.872(0.318)$ & $0.854(0.336)$ & $0.846(0.346)$ & 1.000 & $1.000(0.322)$ & $1.000(0.335)$ & $1.000(0.343)$ \\
\hline & 0.2 & 0.869 & $0.885(0.318)$ & $0.867(0.336)$ & $0.858(0.346)$ & 1.000 & $1.000(0.324)$ & $1.000(0.335)$ & $1.000(0.341)$ \\
\hline & 0.3 & 0.882 & $0.897(0.318)$ & $0.879(0.336)$ & $0.871(0.346)$ & 1.000 & $1.000(0.322)$ & $1.000(0.335)$ & $1.000(0.343)$ \\
\hline & 0.4 & 0.895 & $0.910(0.318)$ & $0.892(0.336)$ & $0.883(0.346)$ & 1.000 & $1.000(0.323)$ & $1.000(0.335)$ & $1.000(0.342)$ \\
\hline & 0.5 & 0.908 & $0.923(0.318)$ & $0.905(0.336)$ & $0.896(0.346)$ & 1.000 & $1.000(0.323)$ & $1.000(0.335)$ & $1.000(0.342)$ \\
\hline
\end{tabular}


Table 2. Cont.

\begin{tabular}{|c|c|c|c|c|c|c|c|c|c|}
\hline & 0.6 & 0.921 & $0.937(0.318)$ & $0.918(0.336)$ & $0.909(0.346)$ & 1.000 & $1.000(0.323)$ & $1.000(0.335)$ & $1.000(0.342)$ \\
\hline & 0.7 & 0.934 & $0.950(0.318)$ & $0.931(0.336)$ & $0.922(0.346)$ & 1.000 & $1.000(0.321)$ & $1.000(0.335)$ & $1.000(0.344)$ \\
\hline & 0.8 & 0.947 & $0.963(0.318)$ & $0.945(0.336)$ & $0.936(0.346)$ & 0.998 & $1.000(0.322)$ & $1.000(0.335)$ & $0.993(0.343)$ \\
\hline & 0.9 & 0.961 & $0.977(0.318)$ & $0.959(0.336)$ & $0.950(0.346)$ & 0.988 & $1.000(0.319)$ & $0.987(0.336)$ & $0.978(0.345)$ \\
\hline & 1.0 & 0.975 & $0.991(0.318)$ & $0.973(0.336)$ & $0.964(0.346)$ & 0.975 & $0.991(0.318)$ & $0.973(0.336)$ & $0.964(0.346)$ \\
\hline \multirow[t]{11}{*}{5} & 0.0 & 0.889 & $0.903(0.323)$ & $0.860(0.358)$ & $0.908(0.319)$ & 1.000 & $1.000(0.327)$ & $1.000(0.349)$ & $1.000(0.324)$ \\
\hline & 0.1 & 0.902 & $0.915(0.323)$ & $0.872(0.358)$ & $0.921(0.319)$ & 1.000 & $1.000(0.332)$ & $1.000(0.353)$ & $1.000(0.315)$ \\
\hline & 0.2 & 0.910 & $0.895(0.330)$ & $0.848(0.366)$ & $1.000(0.304)$ & 1.000 & $1.000(0.332)$ & $1.000(0.350)$ & $1.000(0.318)$ \\
\hline & 0.3 & 0.919 & $0.898(0.329)$ & $0.869(0.366)$ & $1.000(0.305)$ & 1.000 & $1.000(0.323)$ & $1.000(0.353)$ & $1.000(0.325)$ \\
\hline & 0.4 & 0.928 & $0.911(0.329)$ & $0.883(0.364)$ & $1.000(0.307)$ & 1.000 & $1.000(0.326)$ & $1.000(0.351)$ & $1.000(0.323)$ \\
\hline & 0.5 & 0.938 & $0.925(0.327)$ & $0.896(0.364)$ & $1.000(0.309)$ & 1.000 & $1.000(0.327)$ & $1.000(0.349)$ & $1.000(0.324)$ \\
\hline & 0.6 & 0.947 & $0.939(0.327)$ & $0.909(0.362)$ & $1.000(0.311)$ & 1.000 & $1.000(0.326)$ & $1.000(0.351)$ & $1.000(0.323)$ \\
\hline & 0.7 & 0.957 & $0.953(0.326)$ & $0.923(0.361)$ & $1.000(0.313)$ & 1.000 & $1.000(0.326)$ & $1.000(0.353)$ & $1.000(0.321)$ \\
\hline & 0.8 & 0.967 & $0.967(0.325)$ & $0.937(0.360)$ & $1.000(0.315)$ & 0.998 & $1.000(0.325)$ & $0.995(0.354)$ & $1.000(0.321)$ \\
\hline & 0.9 & 0.977 & $0.981(0.324)$ & $0.951(0.359)$ & $1.000(0.317)$ & 0.993 & $1.000(0.324)$ & $0.981(0.356)$ & $1.000(0.320)$ \\
\hline & 1.0 & 0.987 & $0.996(0.323)$ & $0.966(0.358)$ & $1.000(0.319)$ & 0.987 & $0.996(0.323)$ & $0.966(0.358)$ & $1.000(0.319)$ \\
\hline FMS & $\alpha$ & $\left(E_{k}\right)_{\alpha}^{L}$ & $\left(E_{k}^{(1)}\right)_{\alpha}^{L}$ & $\left(E_{k}^{(2)}\right)_{\alpha}^{L}$ & $\left(E_{k}^{(3)}\right)_{\alpha}^{L}$ & $\left(E_{k}\right)_{\alpha}^{U}$ & $\left(E_{k}^{(1)}\right)_{\alpha}^{U}$ & $\left(E_{k}^{(2)}\right)_{\alpha}^{U}$ & $\left(E_{k}^{(3)}\right)_{\alpha}^{U}$ \\
\hline \multirow[t]{11}{*}{6} & 0.0 & 0.839 & $0.844(0.317)$ & $0.838(0.335)$ & $0.834(0.348)$ & 1.000 & $1.000(0.318)$ & $1.000(0.335)$ & $1.000(0.347)$ \\
\hline & 0.1 & 0.850 & $0.856(0.317)$ & $0.850(0.335)$ & $0.846(0.348)$ & 1.000 & $1.000(0.318)$ & $1.000(0.335)$ & $1.000(0.347)$ \\
\hline & 0.2 & 0.862 & $0.868(0.317)$ & $0.862(0.335)$ & $0.858(0.348)$ & 1.000 & $1.000(0.318)$ & $1.000(0.335)$ & $1.000(0.347)$ \\
\hline & 0.3 & 0.874 & $0.880(0.317)$ & $0.874(0.335)$ & $0.870(0.348)$ & 1.000 & $1.000(0.318)$ & $1.000(0.335)$ & $1.000(0.347)$ \\
\hline & 0.4 & 0.886 & $0.892(0.317)$ & $0.886(0.335)$ & $0.882(0.348)$ & 1.000 & $1.000(0.318)$ & $1.000(0.335)$ & $1.000(0.347)$ \\
\hline & 0.5 & 0.899 & $0.904(0.317)$ & $0.898(0.335)$ & $0.894(0.348)$ & 1.000 & $1.000(0.318)$ & $1.000(0.335)$ & $1.000(0.347)$ \\
\hline & 0.6 & 0.911 & $0.922(0.316)$ & $0.910(0.335)$ & $0.903(0.349)$ & 1.000 & $1.000(0.318)$ & $1.000(0.335)$ & $1.000(0.347)$ \\
\hline & 0.7 & 0.925 & $0.935(0.316)$ & $0.924(0.335)$ & $0.916(0.349)$ & 1.000 & $1.000(0.318)$ & $1.000(0.335)$ & $1.000(0.347)$ \\
\hline & 0.8 & 0.939 & $0.947(0.316)$ & $0.938(0.335)$ & $0.932(0.349)$ & 0.995 & $1.000(0.317)$ & $0.996(0.334)$ & $0.990(0.349)$ \\
\hline & 0.9 & 0.953 & $0.961(0.316)$ & $0.952(0.335)$ & $0.946(0.349)$ & 0.982 & $0.991(0.316)$ & $0.981(0.335)$ & $0.975(0.349)$ \\
\hline & 1.0 & 0.967 & $0.976(0.316)$ & $0.967(0.335)$ & $0.960(0.349)$ & 0.967 & $0.976(0.316)$ & $0.967(0.335)$ & $0.960(0.349)$ \\
\hline \multirow[t]{11}{*}{7} & 0.0 & 0.887 & $0.899(0.321)$ & $0.864(0.361)$ & $0.902(0.318)$ & 1.000 & $1.000(0.321)$ & $1.000(0.360)$ & $1.000(0.319)$ \\
\hline & 0.1 & 0.900 & $0.911(0.321)$ & $0.876(0.361)$ & $0.915(0.318)$ & 1.000 & $1.000(0.325)$ & $1.000(0.352)$ & $1.000(0.323)$ \\
\hline & 0.2 & 0.912 & $0.924(0.321)$ & $0.889(0.361)$ & $0.927(0.318)$ & 1.000 & $1.000(0.325)$ & $1.000(0.353)$ & $1.000(0.323)$ \\
\hline & 0.3 & 0.926 & $0.936(0.321)$ & $0.905(0.361)$ & $0.939(0.318)$ & 1.000 & $1.000(0.321)$ & $1.000(0.360)$ & $1.000(0.319)$ \\
\hline & 0.4 & 0.939 & $0.949(0.321)$ & $0.918(0.361)$ & $0.952(0.318)$ & 1.000 & $1.000(0.321)$ & $1.000(0.360)$ & $1.000(0.319)$ \\
\hline & 0.5 & 0.948 & $0.931(0.326)$ & $0.919(0.362)$ & $1.000(0.312)$ & 1.000 & $1.000(0.321)$ & $1.000(0.360)$ & $1.000(0.319)$ \\
\hline & 0.6 & 0.957 & $0.944(0.326)$ & $0.932(0.361)$ & $1.000(0.313)$ & 1.000 & $1.000(0.321)$ & $1.000(0.360)$ & $1.000(0.319)$ \\
\hline & 0.7 & 0.967 & $0.958(0.325)$ & $0.946(0.360)$ & $1.000(0.315)$ & 1.000 & $1.000(0.321)$ & $1.000(0.360)$ & $1.000(0.319)$ \\
\hline & 0.8 & 0.976 & $0.971(0.324)$ & $0.959(0.360)$ & $1.000(0.316)$ & 1.000 & $1.000(0.321)$ & $1.000(0.360)$ & $1.000(0.319)$ \\
\hline & 0.9 & 0.986 & $0.985(0.323)$ & $0.973(0.359)$ & $1.000(0.318)$ & 1.000 & $1.000(0.321)$ & $1.000(0.360)$ & $1.000(0.319)$ \\
\hline & 1.0 & 0.995 & $0.999(0.323)$ & $0.987(0.358)$ & $1.000(0.319)$ & 0.995 & $0.999(0.323)$ & $0.987(0.358)$ & $1.000(0.319)$ \\
\hline \multirow[t]{11}{*}{8} & 0.0 & 0.825 & $0.818(0.338)$ & $0.825(0.334)$ & $0.834(0.328)$ & 1.000 & $1.000(0.336)$ & $1.000(0.334)$ & $1.000(0.330)$ \\
\hline & 0.1 & 0.836 & $0.829(0.338)$ & $0.835(0.334)$ & $0.845(0.328)$ & 1.000 & $1.000(0.336)$ & $1.000(0.334)$ & $1.000(0.330)$ \\
\hline & 0.2 & 0.848 & $0.840(0.338)$ & $0.847(0.334)$ & $0.856(0.328)$ & 1.000 & $1.000(0.336)$ & $1.000(0.334)$ & $1.000(0.330)$ \\
\hline & 0.3 & 0.859 & $0.851(0.338)$ & $0.858(0.334)$ & $0.867(0.328)$ & 1.000 & $1.000(0.336)$ & $1.000(0.334)$ & $1.000(0.330)$ \\
\hline & 0.4 & 0.870 & $0.863(0.338)$ & $0.869(0.334)$ & $0.879(0.328)$ & 1.000 & $1.000(0.336)$ & $1.000(0.334)$ & $1.000(0.330)$ \\
\hline & 0.5 & 0.882 & $0.874(0.338)$ & $0.881(0.334)$ & $0.890(0.328)$ & 1.000 & $1.000(0.336)$ & $1.000(0.334)$ & $1.000(0.330)$ \\
\hline & 0.6 & 0.893 & $0.886(0.338)$ & $0.892(0.334)$ & $0.902(0.328)$ & 0.992 & $0.986(0.338)$ & $0.992(0.334)$ & $1.000(0.328)$ \\
\hline & 0.7 & 0.906 & $0.898(0.338)$ & $0.905(0.334)$ & $0.915(0.328)$ & 0.980 & $0.971(0.338)$ & $0.979(0.334)$ & $0.989(0.328)$ \\
\hline & 0.8 & 0.917 & 0.909 (0.338) & $0.916(0.334)$ & $0.926(0.328)$ & 0.967 & $0.959(0.338)$ & $0.966(0.334)$ & $0.976(0.328)$ \\
\hline & 0.9 & 0.929 & $0.921(0.338)$ & $0.928(0.334)$ & $0.938(0.328)$ & 0.954 & $0.946(0.338)$ & $0.953(0.334)$ & $0.963(0.328)$ \\
\hline & 1.0 & 0.941 & $0.933(0.338)$ & $0.940(0.334)$ & $0.951(0.328)$ & 0.941 & $0.933(0.338)$ & $0.940(0.334)$ & $0.951(0.328)$ \\
\hline \multirow[t]{11}{*}{9} & 0.0 & 0.719 & $0.715(0.324)$ & $0.713(0.319)$ & $0.727(0.357)$ & 0.972 & $0.967(0.325)$ & $0.963(0.319)$ & $0.986(0.356)$ \\
\hline & 0.1 & 0.730 & $0.726(0.324)$ & $0.724(0.319)$ & $0.738(0.357)$ & 0.958 & $0.952(0.325)$ & 0.949 (0.319) & $0.971(0.356)$ \\
\hline & 0.2 & 0.741 & $0.738(0.324)$ & $0.735(0.319)$ & $0.749(0.357)$ & 0.944 & $0.938(0.325)$ & 0.935 (0.319) & $0.957(0.356)$ \\
\hline & 0.3 & 0.752 & $0.749(0.324)$ & $0.747(0.319)$ & $0.761(0.357)$ & 0.930 & $0.924(0.325)$ & $0.921(0.319)$ & $0.942(0.356)$ \\
\hline & 0.4 & 0.764 & $0.760(0.324)$ & $0.758(0.319)$ & $0.773(0.357)$ & 0.916 & $0.911(0.325)$ & 0.907 (0.319) & $0.928(0.356)$ \\
\hline & 0.5 & 0.776 & $0.772(0.324)$ & $0.770(0.319)$ & $0.785(0.357)$ & 0.902 & $0.897(0.325)$ & $0.894(0.319)$ & $0.914(0.356)$ \\
\hline & 0.6 & 0.789 & $0.785(0.324)$ & $0.783(0.319)$ & $0.799(0.357)$ & 0.889 & $0.884(0.325)$ & $0.881(0.319)$ & $0.900(0.356)$ \\
\hline & 0.7 & 0.800 & $0.796(0.324)$ & $0.793(0.319)$ & $0.809(0.357)$ & 0.876 & $0.871(0.325)$ & $0.868(0.319)$ & $0.887(0.356)$ \\
\hline & 0.8 & 0.812 & $0.808(0.324)$ & $0.805(0.319)$ & $0.822(0.357)$ & 0.862 & $0.858(0.324)$ & 0.855 (0.319) & $0.874(0.357)$ \\
\hline & 0.9 & 0.824 & $0.820(0.324)$ & $0.817(0.319)$ & $0.834(0.357)$ & 0.850 & $0.845(0.324)$ & $0.842(0.319)$ & $0.860(0.357)$ \\
\hline & 1.0 & 0.837 & $0.832(0.324)$ & $0.830(0.319)$ & 0.847 (0.357) & 0.837 & $0.832(0.324)$ & $0.830(0.319)$ & $0.847(0.357)$ \\
\hline \multirow[t]{4}{*}{10} & 0.0 & 0.714 & $0.718(0.324)$ & $0.710(0.342)$ & $0.714(0.334)$ & 0.950 & $0.954(0.324)$ & $0.945(0.342)$ & $0.950(0.334)$ \\
\hline & 0.1 & 0.724 & $0.728(0.324)$ & $0.720(0.342)$ & $0.724(0.334)$ & 0.936 & $0.941(0.324)$ & $0.932(0.342)$ & $0.936(0.334)$ \\
\hline & 0.2 & 0.735 & $0.739(0.324)$ & $0.734(0.342)$ & $0.714(0.334)$ & 0.923 & $0.928(0.324)$ & $0.919(0.342)$ & $0.923(0.334)$ \\
\hline & 0.3 & 0.745 & $0.749(0.324)$ & $0.741(0.342)$ & $0.745(0.334)$ & 0.910 & $0.915(0.324)$ & $0.906(0.342)$ & $0.910(0.334)$ \\
\hline
\end{tabular}


Table 2. Cont

\begin{tabular}{|c|c|c|c|c|c|c|c|c|c|}
\hline & 0.4 & 0.756 & $0.760(0.324)$ & $0.752(0.342)$ & $0.756(0.334)$ & 0.897 & $0.902(0.324)$ & $0.893(0.342)$ & $0.897(0.334)$ \\
\hline & 0.5 & 0.767 & $0.771(0.324)$ & $0.763(0.342)$ & $0.767(0.334)$ & 0.885 & $0.889(0.324)$ & $0.881(0.342)$ & $0.884(0.334)$ \\
\hline & 0.6 & 0.778 & $0.782(0.324)$ & $0.774(0.342)$ & $0.778(0.334)$ & 0.872 & $0.877(0.324)$ & $0.868(0.342)$ & $0.872(0.334)$ \\
\hline & 0.7 & 0.789 & $0.794(0.324)$ & $0.785(0.342)$ & $0.789(0.334)$ & 0.860 & $0.864(0.324)$ & $0.856(0.342)$ & $0.860(0.334)$ \\
\hline & 0.8 & 0.801 & $0.805(0.324)$ & $0.797(0.342)$ & $0.800(0.334)$ & 0.848 & $0.852(0.324)$ & $0.844(0.342)$ & $0.847(0.334)$ \\
\hline & 0.9 & 0.812 & $0.817(0.324)$ & $0.808(0.342)$ & $0.812(0.334)$ & 0.836 & $0.840(0.324)$ & $0.832(0.342)$ & $0.836(0.334)$ \\
\hline & 1.0 & 0.824 & $0.828(0.324)$ & $0.820(0.342)$ & $0.824(0.334)$ & 0.824 & $0.828(0.324)$ & $0.820(0.342)$ & $0.824(0.334)$ \\
\hline FMS & $\alpha$ & $\left(E_{k}\right)_{\alpha}^{L}$ & $\left(E_{k}^{(1)}\right)_{\alpha}^{L}$ & $\left(E_{k}^{(2)}\right)_{\alpha}^{L}$ & $\left(E_{k}^{(3)}\right)_{\alpha}^{L}$ & $\left(E_{k}\right)_{\alpha}^{U}$ & $\left(E_{k}^{(1)}\right)_{\alpha}^{U}$ & $\left(E_{k}^{(2)}\right)_{\alpha}^{U}$ & $\left(E_{k}^{(3)}\right)_{\alpha}^{U}$ \\
\hline \multirow[t]{11}{*}{11} & 0.0 & 0.821 & $0.826(0.330)$ & $0.833(0.326)$ & $0.806(0.344)$ & 1.000 & $1.000(0.332)$ & $1.000(0.331)$ & $1.000(0.337)$ \\
\hline & 0.1 & 0.832 & $0.837(0.330)$ & $0.843(0.326)$ & $0.816(0.344)$ & 1.000 & $1.000(0.332)$ & $1.000(0.331)$ & $1.000(0.337)$ \\
\hline & 0.2 & 0.842 & $0.847(0.330)$ & $0.854(0.326)$ & $0.826(0.344)$ & 1.000 & $1.000(0.332)$ & $1.000(0.331)$ & $1.000(0.337)$ \\
\hline & 0.3 & 0.853 & $0.858(0.330)$ & $0.865(0.326)$ & $0.837(0.344)$ & 0.999 & $1.000(0.332)$ & $1.000(0.331)$ & $0.998(0.337)$ \\
\hline & 0.4 & 0.864 & $0.869(0.330)$ & $0.875(0.326)$ & $0.847(0.344)$ & 0.995 & $1.000(0.331)$ & $1.000(0.329)$ & $0.986(0.340)$ \\
\hline & 0.5 & 0.874 & $0.880(0.330)$ & $0.886(0.326)$ & $0.858(0.344)$ & 0.991 & $0.999(0.329)$ & $1.000(0.328)$ & $0.973(0.343)$ \\
\hline & 0.6 & 0.885 & $0.891(0.330)$ & $0.898(0.326)$ & $0.869(0.344)$ & 0.980 & $0.986(0.330)$ & $0.994(0.326)$ & $0.961(0.344)$ \\
\hline & 0.7 & 0.897 & $0.902(0.330)$ & $0.909(0.326)$ & $0.880(0.344)$ & 0.967 & $0.973(0.330)$ & $0.981(0.326)$ & $0.948(0.344)$ \\
\hline & 0.8 & 0.908 & $0.913(0.330)$ & $0.920(0.326)$ & $0.891(0.344)$ & 0.955 & $0.961(0.330)$ & $0.968(0.326)$ & $0.937(0.344)$ \\
\hline & 0.9 & 0.919 & $0.925(0.330)$ & $0.932(0.326)$ & $0.902(0.344)$ & 0.943 & $0.948(0.330)$ & $0.956(0.326)$ & $0.925(0.344)$ \\
\hline & 1.0 & 0.931 & $0.937(0.330)$ & $0.944(0.326)$ & $0.914(0.344)$ & 0.931 & $0.937(0.330)$ & $0.944(0.326)$ & $0.914(0.344)$ \\
\hline \multirow[t]{11}{*}{12} & 0.0 & 0.679 & $0.690(0.324)$ & $0.675(0.337)$ & $0.672(0.340)$ & 0.896 & $0.905(0.324)$ & $0.893(0.336)$ & $0.890(0.340)$ \\
\hline & 0.1 & 0.688 & $0.699(0.324)$ & $0.684(0.337)$ & $0.680(0.340)$ & 0.883 & $0.892(0.324)$ & $0.880(0.336)$ & $0.877(0.340)$ \\
\hline & 0.2 & 0.697 & $0.708(0.324)$ & $0.693(0.337)$ & $0.689(0.340)$ & 0.870 & $0.879(0.324)$ & $0.867(0.336)$ & $0.864(0.340)$ \\
\hline & 0.3 & 0.706 & $0.717(0.324)$ & $0.702(0.337)$ & $0.698(0.340)$ & 0.858 & $0.867(0.324)$ & $0.855(0.336)$ & $0.852(0.340)$ \\
\hline & 0.4 & 0.715 & $0.726(0.324)$ & $0.711(0.337)$ & $0.707(0.340)$ & 0.845 & $0.854(0.324)$ & $0.843(0.336)$ & $0.840(0.340)$ \\
\hline & 0.5 & 0.724 & $0.733(0.324)$ & $0.721(0.337)$ & $0.718(0.340)$ & 0.833 & $0.843(0.324)$ & $0.830(0.336)$ & $0.827(0.340)$ \\
\hline & 0.6 & 0.738 & $0.750(0.324)$ & $0.734(0.337)$ & $0.731(0.340)$ & 0.822 & $0.831(0.324)$ & $0.818(0.336)$ & $0.816(0.340)$ \\
\hline & 0.7 & 0.745 & $0.754(0.324)$ & $0.742(0.337)$ & $0.739(0.340)$ & 0.810 & $0.820(0.324)$ & $0.807(0.336)$ & $0.804(0.340)$ \\
\hline & 0.8 & 0.755 & $0.765(0.324)$ & $0.752(0.337)$ & $0.749(0.340)$ & 0.799 & $0.809(0.324)$ & $0.795(0.336)$ & $0.792(0.340)$ \\
\hline & 0.9 & 0.766 & $0.775(0.324)$ & $0.763(0.337)$ & $0.760(0.340)$ & 0.788 & $0.797(0.324)$ & $0.784(0.336)$ & $0.781(0.340)$ \\
\hline & 1.0 & 0.777 & $0.786(0.324)$ & $0.773(0.337)$ & $0.770(0.340)$ & 0.777 & $0.786(0.324)$ & $0.773(0.337)$ & $0.770(0.340)$ \\
\hline
\end{tabular}

As stated previously, the proposed model can calculate the overall and DMs' efficiency scores and establish a weighted average relationship between them. This phenomenon can be verified by multiplying the DMs' efficiencies of each FMS by their associated weights, which are the values shown in the parentheses of Table 2, and then by summing up these three DMs to get the overall efficiency scores. For an example of FMS alternative No. 9, at $\alpha=0$, the three DMs' lower bound efficiencies are $0.715,0.713$, and 0.727 , respectively, and their associated weights are $0.324,0.319$, and 0.357 , respectively. The weighted average of the overall efficiency of FMS alternative No. 9 is $0.715 \times 0.324+0.713 \times 0.319+0.727 \times$ 0.357 , or 0.719 , which is exactly its overall efficiency. Similarly, the three DMs' upper bound efficiencies are $0.967,0.963$, and 0.986 , with the corresponding weights $0.325,0.319$, and 0.356 , respectively. The weighted average is $0.967 \times 0.325+0.963 \times 0.319+0.986 \times 0.356=$ 0.972 . This value is exactly the upper bound of the overall efficiency. This relationship is true for every FMS's lower bound and upper bound efficiency scores of at all $\alpha$ values.

In (19), Chen and Klein [45] believe that three or four $\alpha$-cuts are sufficient to discriminate the differences. Since we have the fuzzy overall efficiency scores of the FMS alternatives at eleven distinctive $\alpha$ values, the number of $\alpha$-cuts is set to 10 in (19). In this example, $\beta=0.679$ and $\gamma=1.0$, and the ranking indices $I\left(\widetilde{E}_{j}\right)$ of the 12 FMS alternatives are calculated as shown in the second last column of Table 3. The values in the parentheses are $\left(E_{j}\right)_{\alpha_{i}}^{L}-\gamma$ and $\left(E_{j}\right)_{\alpha_{i}}^{U}-\beta$, respectively, and their associated total values $I\left(E_{j}^{L}\right)=$ $\sum_{i=0}^{10}\left(\left(E_{j}\right)_{\alpha_{i}}^{L}-\gamma\right)$ and $I\left(E_{j}^{U}\right)=\sum_{i=0}^{10}\left(\left(E_{j}\right)_{\alpha_{i}}^{U}-\beta\right)$ are also represented under the heading "Total" in Table 3, respectively. For FMS alternative 1, the associated ranking values are $I\left(E_{1}^{L}\right)=-0.987$ and $I\left(E_{1}^{U}\right)=3.438$. According to Equation (20), the final ranking index $I\left(\widetilde{E}_{1}\right)=I\left(E_{1}^{U}\right) /\left(I\left(E_{1}^{U}\right)-I\left(E_{1}^{L}\right)\right)=3.438 /(3.438+0.987)=0.7769$. Based on the ranking indices, the 12 FMS alternatives have ranked accordingly. Since the larger value of the ranking index, the better the FMS alternative is. FMS no. 7 is the best, followed by FMS 
alternatives 5 and 1 . In other words, FMS no. 7 is the most preferred one for all the FMS alternatives.

Table 3. The fuzzy overall efficiency at eleven distinctive $\alpha$-levels and the ranking of the twelve FMS alternatives.

\begin{tabular}{|c|c|c|c|c|c|c|c|c|c|c|c|c|c|c|c|}
\hline Robot & & $\alpha=0.0$ & $\alpha=0.1$ & $\alpha=0.2$ & $\alpha=0.3$ & $\alpha=0.4$ & $\alpha=0.5$ & $\alpha=0.6$ & $\alpha=0.7$ & $\alpha=0.8$ & $\alpha=0.9$ & $\alpha=1.0$ & Total & $I$ & Rank \\
\hline 1 & $\begin{array}{l}\mathrm{L} \\
\mathrm{U}\end{array}$ & $\begin{array}{c}0.857 \\
(-0.143) \\
1.000 \\
(0.321)\end{array}$ & $\begin{array}{c}0.863 \\
(-0.137) \\
1.000 \\
(0.321)\end{array}$ & $\begin{array}{c}0.879 \\
(-0.121) \\
1.000 \\
(0.321)\end{array}$ & $\begin{array}{c}0.885 \\
(-0.115) \\
1.000 \\
(0.321)\end{array}$ & $\begin{array}{c}0.896 \\
(-0.104) \\
1.000 \\
(0.321)\end{array}$ & $\begin{array}{c}0.913 \\
(-0.087) \\
0.997 \\
(0.318)\end{array}$ & $\begin{array}{c}0.925 \\
(-0.075) \\
0.992 \\
(0.313)\end{array}$ & $\begin{array}{c}0.931 \\
(-0.069) \\
0.988 \\
(0.309)\end{array}$ & $\begin{array}{c}0.943 \\
(-0.057) \\
0.983 \\
(0.304)\end{array}$ & $\begin{array}{c}0.955 \\
(-0.045) \\
0.979 \\
(0.300)\end{array}$ & $\begin{array}{c}0.967 \\
(-0.033) \\
0.967 \\
(0.288)\end{array}$ & $\begin{array}{l}(-0.987) \\
(3.438)\end{array}$ & 0.7769 & 3 \\
\hline 2 & $\begin{array}{l}\mathrm{L} \\
\mathrm{U}\end{array}$ & $\begin{array}{c}0.837 \\
(-0.163) \\
1.000 \\
(0.321)\end{array}$ & $\begin{array}{c}0.848 \\
(-0.152) \\
1.000 \\
(0.321)\end{array}$ & $\begin{array}{c}0.859 \\
(-0.141) \\
1.000 \\
(0.321)\end{array}$ & $\begin{array}{c}0.870 \\
(-0.130) \\
1.000 \\
(0.321)\end{array}$ & $\begin{array}{c}0.881 \\
(-0.119) \\
1.000 \\
(0.321)\end{array}$ & $\begin{array}{c}0.892 \\
(-0.108) \\
0.997 \\
(0.318)\end{array}$ & $\begin{array}{c}0.903 \\
(-0.097) \\
0.992 \\
(0.313)\end{array}$ & $\begin{array}{c}0.915 \\
(-0.085) \\
0.986 \\
(0.307)\end{array}$ & $\begin{array}{c}0.926 \\
(-0.074) \\
0.975 \\
(0.296)\end{array}$ & $\begin{array}{c}0.938 \\
(-0.062) \\
0.962 \\
(0.300)\end{array}$ & $\begin{array}{c}0.950 \\
(-0.050) \\
0.950 \\
(0.288)\end{array}$ & $\begin{array}{l}(-1.182) \\
(3.395)\end{array}$ & 0.7417 & 7 \\
\hline 3 & $\begin{array}{l}\mathrm{L} \\
\mathrm{U}\end{array}$ & $\begin{array}{c}0.848 \\
(-0.152) \\
1.000 \\
(0.321)\end{array}$ & $\begin{array}{c}0.859 \\
(-0.141) \\
1.000 \\
(0.321)\end{array}$ & $\begin{array}{c}0.870 \\
(-0.130) \\
1.000 \\
(0.321)\end{array}$ & $\begin{array}{c}0.882 \\
(-0.118) \\
1.000 \\
(0.321)\end{array}$ & $\begin{array}{c}0.894 \\
(-0.106) \\
1.000 \\
(0.321)\end{array}$ & $\begin{array}{c}0.905 \\
(-0.095) \\
1.000 \\
(0.321)\end{array}$ & $\begin{array}{c}0.917 \\
(-0.083) \\
1.000 \\
(0.321)\end{array}$ & $\begin{array}{c}0.930 \\
(-0.070) \\
0.997 \\
(0.318)\end{array}$ & $\begin{array}{c}0.942 \\
(-0.058) \\
0.990 \\
(0.311)\end{array}$ & $\begin{array}{c}0.954 \\
(-0.046) \\
0.980 \\
(0.301)\end{array}$ & $\begin{array}{c}0.967 \\
(-0.033) \\
0.967 \\
(0.288)\end{array}$ & $\begin{array}{l}(-1.032) \\
(3.467)\end{array}$ & 0.7707 & 5 \\
\hline 4 & $\begin{array}{l}\mathrm{L} \\
\mathrm{U}\end{array}$ & $\begin{array}{c}0.845 \\
(-0.155) \\
1.000 \\
(0.321)\end{array}$ & $\begin{array}{c}0.857 \\
(-0.143) \\
1.000 \\
(0.321)\end{array}$ & $\begin{array}{c}0.869 \\
(-0.131) \\
1.000 \\
(0.321)\end{array}$ & $\begin{array}{c}0.882 \\
(-0.118) \\
1.000 \\
(0.321)\end{array}$ & $\begin{array}{c}0.895 \\
(-0.105) \\
1.000 \\
(0.321)\end{array}$ & $\begin{array}{c}0.908 \\
(-0.092) \\
1.000 \\
(0.321)\end{array}$ & $\begin{array}{c}0.921 \\
(-0.079) \\
1.000 \\
(0.321)\end{array}$ & $\begin{array}{c}0.934 \\
(-0.066 \\
1.000 \\
(0.321)\end{array}$ & $\begin{array}{c}0.947 \\
(-0.053) \\
0.998 \\
(0.319)\end{array}$ & $\begin{array}{c}0.961 \\
(-0.039) \\
0.988 \\
(0.309)\end{array}$ & $\begin{array}{c}0.975 \\
(-0.025) \\
0.975 \\
(0.297)\end{array}$ & $\begin{array}{l}(-1.005) \\
(3.495)\end{array}$ & 0.7766 & 4 \\
\hline 5 & $\begin{array}{l}\mathrm{L} \\
\mathrm{U}\end{array}$ & $\begin{array}{c}0.889 \\
(-0.111) \\
1.000 \\
(0.321)\end{array}$ & $\begin{array}{c}0.902 \\
(-0.098) \\
1.000 \\
(0.321)\end{array}$ & $\begin{array}{c}0.910 \\
(-0.090) \\
1.000 \\
(0.321)\end{array}$ & $\begin{array}{c}0.919 \\
(-0.081) \\
1.000 \\
(0.321)\end{array}$ & $\begin{array}{c}0.928 \\
(-0.072) \\
1.000 \\
(0.321)\end{array}$ & $\begin{array}{c}0.938 \\
(-0.062) \\
1.000 \\
(0.321)\end{array}$ & $\begin{array}{c}0.947 \\
(-0.053) \\
1.000 \\
(0.321)\end{array}$ & $\begin{array}{c}0.957 \\
(-0.043) \\
1.000 \\
(0.321)\end{array}$ & $\begin{array}{c}0.967 \\
(-0.033) \\
0.998 \\
(0.320)\end{array}$ & $\begin{array}{c}0.977 \\
(-0.023) \\
0.993 \\
(0.314)\end{array}$ & $\begin{array}{c}0.986 \\
(-0.014) \\
0.986 \\
(0.308)\end{array}$ & $\begin{array}{l}(-0.682) \\
(3.511)\end{array}$ & 0.8374 & 2 \\
\hline 6 & $\begin{array}{l}\mathrm{L} \\
\mathrm{U}\end{array}$ & $\begin{array}{c}0.839 \\
(-0.161) \\
1.000 \\
(0.321)\end{array}$ & $\begin{array}{c}0.850 \\
(-0.150) \\
1.000 \\
(0.321)\end{array}$ & $\begin{array}{c}0.862 \\
(-0.138) \\
1.000 \\
(0.321)\end{array}$ & $\begin{array}{c}0.874 \\
(-0.126) \\
1.000 \\
(0.321)\end{array}$ & $\begin{array}{c}0.886 \\
(-0.114) \\
1.000 \\
(0.321)\end{array}$ & $\begin{array}{c}0.899 \\
(-0.101) \\
1.000 \\
(0.321)\end{array}$ & $\begin{array}{c}0.911 \\
(-0.089) \\
1.000 \\
(0.321)\end{array}$ & $\begin{array}{c}0.925 \\
(-0.075) \\
1.000 \\
(0.321)\end{array}$ & $\begin{array}{c}0.939 \\
(-0.061) \\
0.995 \\
(0.316)\end{array}$ & $\begin{array}{c}0.953 \\
(-0.047) \\
0.982 \\
(0.303)\end{array}$ & $\begin{array}{c}0.967 \\
(-0.033) \\
0.967 \\
(0.289)\end{array}$ & $\begin{array}{l}(-1.094) \\
(3.478)\end{array}$ & 0.7607 & 6 \\
\hline 7 & $\begin{array}{l}\mathrm{L} \\
\mathrm{U}\end{array}$ & $\begin{array}{c}0.887 \\
(-0.113) \\
1.000 \\
(0.321)\end{array}$ & $\begin{array}{c}0.900 \\
(-0.100) \\
1.000 \\
(0.321)\end{array}$ & $\begin{array}{c}0.912 \\
(-0.088) \\
1.000 \\
(0.321)\end{array}$ & $\begin{array}{c}0.926 \\
(-0.074) \\
1.000 \\
(0.321)\end{array}$ & $\begin{array}{c}0.939 \\
(-0.061) \\
1.000 \\
(0.321)\end{array}$ & $\begin{array}{c}0.948 \\
(-0.052) \\
1.000 \\
(0.321)\end{array}$ & $\begin{array}{c}0.957 \\
(-0.043) \\
1.000 \\
(0.321)\end{array}$ & $\begin{array}{c}0.967 \\
(-0.033) \\
1.000 \\
(0.321)\end{array}$ & $\begin{array}{c}0.976 \\
(-0.024) \\
1.000 \\
(0.321)\end{array}$ & $\begin{array}{c}0.986 \\
(-0.014) \\
1.000 \\
(0.321)\end{array}$ & $\begin{array}{c}0.995 \\
(-0.005) \\
0.995 \\
(0.316)\end{array}$ & $\begin{array}{l}(-0.607) \\
(3.529)\end{array}$ & 0.8531 & 1 \\
\hline 8 & $\begin{array}{l}\mathrm{L} \\
\mathrm{U}\end{array}$ & $\begin{array}{c}0.825 \\
(-0.175) \\
1.000 \\
(0.321)\end{array}$ & $\begin{array}{c}0.836 \\
(-0.164) \\
1.000 \\
(0.321)\end{array}$ & $\begin{array}{c}0.848 \\
(-0.152) \\
1.000 \\
(0.321)\end{array}$ & $\begin{array}{c}0.859 \\
(-0.141) \\
1.000 \\
(0.321)\end{array}$ & $\begin{array}{c}0.870 \\
(-0.130) \\
1.000 \\
(0.321)\end{array}$ & $\begin{array}{c}0.882 \\
(-0.118) \\
1.000 \\
(0.321)\end{array}$ & $\begin{array}{c}0.893 \\
(-0.107) \\
0.992 \\
(0.314)\end{array}$ & $\begin{array}{c}0.906 \\
(-0.094) \\
0.980 \\
(0.301)\end{array}$ & $\begin{array}{c}0.917 \\
(-0.083) \\
0.967 \\
(0.288)\end{array}$ & $\begin{array}{c}0.929 \\
(-0.071) \\
0.954 \\
(0.275)\end{array}$ & $\begin{array}{c}0.941 \\
(-0.059) \\
0.941 \\
(0.263)\end{array}$ & $\begin{array}{l}(-1.294) \\
(3.368)\end{array}$ & 7225 & 8 \\
\hline 9 & $\begin{array}{l}\mathrm{L} \\
\mathrm{U}\end{array}$ & $\begin{array}{c}0.719 \\
(-0.281) \\
0.972 \\
(0.294)\end{array}$ & $\begin{array}{c}0.730 \\
(-0.270) \\
0.958 \\
(0.279)\end{array}$ & $\begin{array}{c}0.741 \\
(-0.259) \\
0.944 \\
(0.265)\end{array}$ & $\begin{array}{c}0.752 \\
(-0.248) \\
0.930 \\
(0.251)\end{array}$ & $\begin{array}{c}0.764 \\
(-0.236) \\
0.916 \\
(0.237)\end{array}$ & $\begin{array}{c}0.776 \\
(-0.224) \\
0.902 \\
(0.223)\end{array}$ & $\begin{array}{c}0.789 \\
(-0.211) \\
0.889 \\
(0.210)\end{array}$ & $\begin{array}{c}0.800 \\
(-0.200) \\
0.876 \\
(0.197)\end{array}$ & $\begin{array}{c}0.812 \\
(-0.188) \\
0.862 \\
(0.184)\end{array}$ & $\begin{array}{c}0.824 \\
(-0.176) \\
0.850 \\
(0.171)\end{array}$ & $\begin{array}{c}0.837 \\
(-0.163) \\
0.837 \\
(0.158)\end{array}$ & $\begin{array}{l}(-2.456) \\
(2.469)\end{array}$ & 0.5013 & 10 \\
\hline 10 & $\begin{array}{l}\mathrm{L} \\
\mathrm{U}\end{array}$ & $\begin{array}{c}0.714 \\
(-0.286) \\
0.950 \\
(0.271)\end{array}$ & $\begin{array}{c}0.724 \\
(-0.276) \\
0.936 \\
(0.257)\end{array}$ & $\begin{array}{c}0.735 \\
(-0.265) \\
0.923 \\
(0.244)\end{array}$ & $\begin{array}{c}0.745 \\
(-0.255) \\
0.910 \\
(0.231)\end{array}$ & $\begin{array}{c}0.756 \\
(-0.244) \\
0.897 \\
(0.218)\end{array}$ & $\begin{array}{c}0.767 \\
(-0.233) \\
0.885 \\
(0.206)\end{array}$ & $\begin{array}{c}0.778 \\
(-0.222) \\
0.872 \\
(0.193)\end{array}$ & $\begin{array}{c}0.789 \\
(-0.211) \\
0.860 \\
(0.181)\end{array}$ & $\begin{array}{c}0.801 \\
(-0.199) \\
0.848 \\
(0.169)\end{array}$ & $\begin{array}{c}0.812 \\
(-0.188) \\
0.836 \\
(0.157)\end{array}$ & $\begin{array}{c}0.824 \\
(-0.176) \\
0.824 \\
(0.145)\end{array}$ & $\begin{array}{l}(-2.556) \\
(2.273)\end{array}$ & 0.4707 & 11 \\
\hline 11 & $\begin{array}{l}\mathrm{L} \\
\mathrm{U}\end{array}$ & $\begin{array}{c}0.821 \\
(-0.178) \\
1.000 \\
(0.321)\end{array}$ & $\begin{array}{c}0.832 \\
(-0.168) \\
1.000 \\
(0.321)\end{array}$ & $\begin{array}{c}0.842 \\
(-0.158) \\
1.000 \\
(0.321)\end{array}$ & $\begin{array}{c}0.853 \\
(-0.147) \\
1.000 \\
(0.321)\end{array}$ & $\begin{array}{c}0.864 \\
(-0.136) \\
0.995 \\
(0.317)\end{array}$ & $\begin{array}{c}0.874 \\
(-0.126) \\
0.991 \\
(0.312)\end{array}$ & $\begin{array}{c}0.885 \\
(-0.115) \\
0.980 \\
(0.301)\end{array}$ & $\begin{array}{c}0.897 \\
(-0.103) \\
0.967 \\
(0.288)\end{array}$ & $\begin{array}{c}0.908 \\
(-0.092) \\
0.955 \\
(0.276)\end{array}$ & $\begin{array}{c}0.919 \\
(-0.081) \\
0.943 \\
(0.264)\end{array}$ & $\begin{array}{c}0.931 \\
(-0.069) \\
0.931 \\
(0.252)\end{array}$ & $\begin{array}{l}(-1.374) \\
(3.295)\end{array}$ & 0.7058 & 9 \\
\hline 12 & $\begin{array}{l}\mathrm{L} \\
\mathrm{U}\end{array}$ & $\begin{array}{c}0.679 \\
(-0.321) \\
0.896 \\
(0.217)\end{array}$ & $\begin{array}{c}0.688 \\
(-0.312) \\
0.883 \\
(0.204)\end{array}$ & $\begin{array}{c}0.697 \\
(-0.303) \\
0.870 \\
(0.191)\end{array}$ & $\begin{array}{c}0.706 \\
(-0.294) \\
0.858 \\
(0.179)\end{array}$ & $\begin{array}{c}0.715 \\
(-0.285) \\
0.845 \\
(0.167)\end{array}$ & $\begin{array}{c}0.724 \\
(-0.276) \\
0.833 \\
(0.154)\end{array}$ & $\begin{array}{c}0.738 \\
(-0.262) \\
0.822 \\
(0.143)\end{array}$ & $\begin{array}{c}0.745 \\
(-0.255) \\
0.810 \\
(0.131)\end{array}$ & $\begin{array}{c}0.755 \\
(-0.245) \\
0.799 \\
(0.120)\end{array}$ & $\begin{array}{c}0.766 \\
(-0.234) \\
0.787 \\
(0.109)\end{array}$ & $\begin{array}{c}0.777 \\
(-223) \\
0.777 \\
(0.098)\end{array}$ & $\begin{array}{l}(-3.012) \\
(1.713)\end{array}$ & .3625 & 12 \\
\hline
\end{tabular}

L: lower bound, U: upper bound.

\section{Conclusions}

When a problem involves complicated decision processes, a group of DMs should achieve better decisions because of having more excellent knowledge. This paper develops a fuzzy network DEA model to select AMT alternatives when the input and output data are fuzzy numbers and collected by multiple DMs. By viewing the multiple DMs as a network one, the data provided by each DM can then be taken into account in evaluating the overall efficiency. Since the assurance region approach is comprehensive to bounding the multipliers, this approach is adopted to impose weight restrictions on the model to improve AMT alternatives' discrimination. A pair of two-level mathematical programs is developed to calculate the lower bound and upper bound of the $\alpha$-cut of the fuzzy overall efficiency. The fuzzy network DEA model proposed in this paper can measure the fuzzy overall and DMs' efficiencies at the same time, and the fuzzy overall efficiency is a weighted average of every DM's fuzzy efficiency. This relationship always exists for the lower bound and upper bound efficiencies of each alternative at all $\alpha$ values. Since the overall efficiency of AMT alternatives are fuzzy numbers, a ranking method is needed to 
distinguish the fuzzy overall efficiency scores. By using the ranking procedure presented in the study, the most preferred AMT system is determined. An example of FMS selection is used to illustrate the approach proposed in this paper.

The proposed methodology can solve real-world problems and can be used for justification and selection problems accounting for multiple DMs with fuzzy inputs and outputs. Moreover, since crisp numbers will always be constant values in all $\alpha$-cuts, they can be considered as degenerate fuzzy numbers with only one value in the domain of fuzzy sets. In other words, the methodology proposed in this paper can then be easily applied to the case of all crisp data contained in the model. In this study, we consider the parallel model only. If a system with two stages, then we cannot apply the approach proposed in this paper. To generalize the developed model to systems with two stages or more than two stages in a fuzzy environment is a direction for further research.

Sustainable manufacturing is the creation of manufactured products through economically sound processes that minimize negative environmental impacts while conserving energy and natural resources. One of the key benefits of sustainable manufacturing is to increase operational efficiency and reducing costs and waste. Additionally, lean manufacturing, which is closely related to sustainable manufacturing, is a business model and collection of tactical methods that emphasize eliminating non-value-added activities (waste) while delivering quality products on time at least cost with greater efficiency. Since the adoption of AMTs can offer significant sustainability and efficiency for sustainable and lean manufacturing, this paper provides a practical decision aid to selecting AMTs. It is helpful for companies to attain a new manufacturing paradigm of sustainable manufacturing.

Funding: No external funding.

Informed Consent Statement: Not applicable.

Data Availability Statement: The utilized data is available under request.

Conflicts of Interest: The author declares no conflict of interest.

\section{References}

1. Gebler, M.; Uiterkamp, A.J.S.; Visser, C. A global sustainability perspective on 3D printing technologies. Energy Policy 2014, 74, 158-167. [CrossRef]

2. Ford, S.; Despeisse, M. Additive manufacturing and sustainability: An exploratory study of the advantages and challenges. $J$. Clean. Prod. 2016, 137, 1573-1587. [CrossRef]

3. Lepore, D.; Micozzi, A.; Spigarelli, F. Industry 4.0 Accelerating Sustainable Manufacturing in the COVID-19 Era: Assessing the Readiness and Responsiveness of Italian Regions. Sustainability 2021, 13, 2670. [CrossRef]

4. Wang, Y.M.; Chin, K.S. A new approach for the selection of advanced manufacturing technologies: DEA with double frontiers. Int. J. Prod. Res. 2009, 47, 6663-6679. [CrossRef]

5. Dyson, R.G.; Allen, R.; Camanho, A.S.; Podinovski, V.V.; Sarrico, C.S.; Shale, E.A. Pitfalls and protocols in DEA. Eur. J. Oper. Res. 2001, 132, 245-259. [CrossRef]

6. Karsak, E.E. A two-phase robot selection procedure. Prod. Plan. Control 1998, 9, 675-684. [CrossRef]

7. Braglia, M.; Petroni, A. Evaluating and selecting investments in industrial robots. Int. J. Prod. Res. 1999, 37, 4157-4178. [CrossRef]

8. Sarkis, J.; Talluri, S. A decision model for evaluation of flexible manufacturing systems in the presence of both cardinal and ordinal factors. Int. J. Prod. Res. 1999, 37, 2927-2938. [CrossRef]

9. Talluri, S.; Yoon, K.P. A cone-ratio DEA approach for AMT justification. Int. J. Prod. Econ. 2000, 66, 119-129. [CrossRef]

10. Talluri, S.; Whiteside, M.M.; Seipel, S.J. A nonparametric stochastic procedure for FMS evaluation. Eur. J. Oper. Res. 2000, 124, 529-538. [CrossRef]

11. Karsak, E.E.; Ahiska, S.S. Practical common weight multi-criteria decision-making approach with an improved discriminating power for technology selection. Int. J. Prod. Res. 2005, 43, 1537-1554. [CrossRef]

12. Amin, G.R.; Toloo, M.; Sohrabi, B. An improved MCDM DEA model for technology selection. Int. J. Prod. Res. 2006, 2681-2686. [CrossRef]

13. Liu, S.T. A fuzzy DEA/AR approach to the selection of flexible manufacturing systems. Comput. Ind. Eng. 2008, 54, 66-76. [CrossRef]

14. Tao, L.; Chen, Y.; Liu, X.; Wang, X. An integrated multiple criteria decision making model applying axiomatic fuzzy set theory. Appl. Math. Model. 2012, 36, 5046-5058. [CrossRef]

15. Hsu, C.Y. Integrated data envelopment analysis and neural network model for forecasting performance of wafer fabrication operations. J. Intell. Manuf. 2014, 25, 945-960. [CrossRef] 
16. Yari, M.; Bagherpour, R.; Jamali, S. Development of an evaluation system for blasting patterns to provide efficiency production. J. Intell. Manuf. 2017, 28, 975-984. [CrossRef]

17. Zimmermann, H.Z. Fuzzy Set Theory and Its Applications, 3rd ed.; Kluwer-Nijhoff: Boston, MA, USA, 1996.

18. Kao, C.; Liu, S.T. Fuzzy efficiency measures in data envelopment analysis. Fuzzy Sets Syst. 2000, 113, 427-437. [CrossRef]

19. Kao, C.; Liu, S.T. Data envelopment analysis with missing data: An application to university libraries in Taiwan. J. Oper. Res. Soc. 2000, 51, 897-905. [CrossRef]

20. Leon, T.; Liern, V.; Ruiz, J.L.; Sirvent, I. A fuzzy mathematical programming approach to the assessment of efficiency with DEA models. Fuzzy Sets Syst. 2003, 139, 407-419. [CrossRef]

21. Lertworasirkul, S.; Fang, S.C.; Joines, J.A.; Nuttle, H.L.W. Fuzzy data envelopment analysis (DEA): A possibility approach. Fuzzy Sets Syst. 2003, 139, 379-394. [CrossRef]

22. Wang, Y.M.; Greatbanks, R.; Yang, J.B. Interval efficiency assessment using data envelopment analysis. Fuzzy Sets Syst. 2005, 153, 347-370. [CrossRef]

23. Guo, P.J. Fuzzy data envelopment analysis and its application to location problems. Inf. Sci. 2009, 179, 820-829. [CrossRef]

24. Wen, M.L.; Li, H.S. Fuzzy data envelopment analysis (DEA): Model and ranking method. J. Comput. Appl. Math. 2009, 223, 872-878. [CrossRef]

25. Hatami-Marbini, A.; Emrouznejad, A.; Tavana, M. A taxonomy and review of the fuzzy data envelopment analysis literature: Two decades in the making. Eur. J. Oper. Res. 2011, 214, 457-472. [CrossRef]

26. Emrouznejad, A.; Tavana, M. Performance Measurement with Fuzzy Data Envelopment Analysis; Springer: Heidelberg, Germany, 2014.

27. Kao, C.; Liu, S.T. Efficiencies of two-stage systems with fuzzy data. Fuzzy Sets Syst. 2011, 176, 20-35. [CrossRef]

28. Kao, C.; Lin, P.H. Efficiency of parallel production systems with fuzzy data. Fuzzy Sets Syst. 2012, 198, 83-98. [CrossRef]

29. Lozano, S. Computing fuzzy process efficiency in parallel systems. Fuzzy Optim. Decis. Mak. 2014, 13, 73-89. [CrossRef]

30. Hatami-Marbinia, A.; Saati, S. Efficiency evaluation in two-stage data envelopment analysis under a fuzzy environment: A common-weights approach. Appl. Soft Comput. 2018, 72, 156-165. [CrossRef]

31. Kao, C. Network Data Envelopment Analysis: Foundations and Extensions; Springer: Cham, Switzerland, 2017.

32. Asmild, M.; Paradi, J.C.; Reese, D.N.; Tam, F. Measuring overall efficiency and effectiveness using DEA. Eur. J. Oper. Res. 2007, 178, 305-321. [CrossRef]

33. Charnes, A.; Cooper, W.W.; Rhodes, E. Measuring the efficiency of decision making units. Eur. J. Oper. Res. 1978, 2, 429-444. [CrossRef]

34. Kao, C. Efficiency measurement for parallel production systems. Eur. J. Oper. Res. 2009, 196, 1107-1112. [CrossRef]

35. Allen, R.; Athanassopoulos, A.; Dyson, R.G.; Thanassoulis, E. Weights restrictions and value judgements in data envelopment analysis: Evolution, development and future directions. Ann. Oper. Res. 1997, 73, 13-34. [CrossRef]

36. Dyson, R.G.; Thanassoulis, E. Reducing weight flexibility in DEA. J. Oper. Res. Soc. 1988, 39, 563-567. [CrossRef]

37. Podinovski, V.V. Side effects of absolute weight bounds in DEA models. Eur. J. Oper. Res. 1999, 115, 583-595. [CrossRef]

38. Wong, Y.H.B.; Beasle, J.E. Restricting weight flexibility in data envelopment analysis. J. Oper. Res. Soc. 1990, 41, 829-835. [CrossRef]

39. Thanassoulis, E.; Portela, M.C.; Allen, R. Incorporating value judgment in DEA. In Handbook on Data Envelopment Analysis; Cooper, W.W., Seiford, L.M., Zhu, J., Eds.; Kluwer Academic Publishers: New York, NY, USA, 2004; pp. 99-138.

40. Thompson, R.G.; Singleton, F.D.; Thrall, R.M.; Smith, B.A. Comparative site evaluations for locating high energy lab in Texas. Interfaces 1986, 16, 1380-1395. [CrossRef]

41. Thompson, R.G.; Langemeier, L.N.; Lee, C.T.; Thrall, R.M. The role of multiplier bounds in efficiency analysis with application to Kansas farming. J. Econ. 1990, 46, 93-108. [CrossRef]

42. Saati, S.; Memariani, A. Reducing weight flexibility in fuzzy DEA. Appl. Math. Comput. 2005, 161, 611-622. [CrossRef]

43. Liu, S.T. Restricting weight flexibility in fuzzy two-stage DEA. Comput. Ind. Eng. 2014, 74, 149-160. [CrossRef]

44. Bazaraa, M.S.; Jarvis, J.J.; Sherali, H.D. Linear Programming and Network Flows, 4th ed.; John Wiley \& Sons: New York, NY, USA, 2009.

45. Chen, C.B.; Klein, C.M. A simple approach to ranking a group of aggregated utilities. IEEE Trans. Syst. Man Cybern. Part B 1997, 27, 26-35. [CrossRef]

46. Abbasbandy, S.; Hahhari, T. A new approach for ranking of trapezoidal fuzzy numbers. Comput. Math. Appl. 2009, 57, 413-419. [CrossRef]

47. Yu, V.F.; Dat, L.Q. An improved ranking method for fuzzy numbers with integral values. Appl. Soft Comput. 2014, 14, 603-608. [CrossRef]

48. Rezvani, S. Ranking generalized exponential trapezoidal fuzzy numbers based on variance. Appl. Math. Comput. 2015, 262, 191-198. [CrossRef]

49. Boulmakou1, A.; Laarabi, M.H.; Sacile, R.; Garbolino, E. An original approach to ranking fuzzy numbers by inclusion index and Biset Encoding. Fuzzy Optim. Decis. Mak. 2017, 16, 23-49. [CrossRef]

50. Chutia, R.; Chutia, B. A new method of ranking parametric form of fuzzy numbers using value and ambiguity. Appl. Soft Comput. 2017, 52, 1154-1168. [CrossRef] 